\title{
Neuronal Loss Induced in Limbic Pathways by Kindling: Evidence for Induction of Hippocampal Sclerosis by Repeated Brief Seizures
}

\author{
Jose E. Cavazos, ${ }^{1.2}$ Indranil Das, and Thomas P. Sutula ${ }^{1}$ \\ ${ }^{1}$ The Neuroscience Training Program and the Departments of Neurology and Anatomy, University of Wisconsin, Madison, \\ Wisconsin 53792 and ${ }^{2}$ Duke University Medical Center, Durham, North Carolina 27710
}

\begin{abstract}
Repeated kindled seizures induce long-lasting physiological and morphological alterations in the hippocampal formation. In the dentate gyrus (DG), the morphological alterations induced by kindled seizures include loss of polymorphic neurons in the hilus, mossy fiber axon sprouting, and synaptic reorganization of the mossy fiber pathway. In this study, quantitative stereological methods were used to determine the distribution and time course of neuronal loss induced by $3, \mathbf{3 0}$, or 150 kindled generalized tonic-clonic seizures in hippocampal, limbic, and neocortical pathways. Neuronal loss was observed in the hilus of the DG and CA1 after three generalized tonic-clonic seizures, and progressed in these sites to $49 \%$ and $44 \%$ of controls after 150 seizures. Neuronal loss was also observed in CA3, entorhinal cortex, and the rostral endopyriform nucleus after 30 seizures, and was detected in the granule cell layer and CA2 after 150 seizures. There was no evidence of neuronal loss in the somatosensory cortex after 150 seizures. The time course of the neuronal loss demonstrated selective vulnerability of hippocampal neuronal populations to seizure-induced injury, and suggests that even brief seizures may induce excitotoxic injury in vulnerable neuronal populations. Repeated brief seizures induced neuronal loss in a distribution that resembled hippocampal sclerosis, the most common lesion observed in human epilepsy. The results demonstrated that kindling induces alterations in neural circuitry in a variety of locations in the limbic system, and suggest that hippocampal sclerosis may be acquired in human epilepsy as a consequence of repeated seizures.
\end{abstract}

IKey words: hippocampus, dentate gyrus, entorhinal cortex, endopyriform nucleus, epilepsy, seizures, kindling, excitotoxicity, cell death, temporal lobe]

Excessive neuronal activation by the excitatory amino acid transmitter glutamate induces neuronal injury and death that has been referred to as excitotoxicity (Olney et al., 1974; Nadler and Cuthbertson, 1980). There has been particular interest in the molecular mechanisms of excitotoxicity, as excitotoxic damage may play a role in human disorders such as stroke, head trauma, and epilepsy (Choi and Rothman, 1990).

Clinical and experimental studies have implicated excitotoxic

\footnotetext{
Received June 24, 1993; revised Sept. 15, 1993; accepted Nov. 1, 1993.

This research was supported by the Klingenstein Fund and the NINDS. We thank L. Haberly and R. Kalil for their helpful comments.

Correspondence should be addressed to Thomas P. Sutula, M.D., Ph.D., Department of Neurology H4/614, University of Wisconsin, Madison, WI 53792.

Copyright (c) 1994 Society for Neuroscience 0270-6474/94/143106-16\$05.00/0
}

mechanisms in the neuronal damage associated with status epilepticus, a severe, sometimes life-threatening condition characterized by prolonged or repetitive seizures that are not followed by return to normal consciousness. Status epilepticus is often followed by extensive neuronal damage involving the hippocampus, other limbic structures, neocortex, and subcortical areas, and by cognitive deficits (Hauser, 1983).

Excitotoxic damage has been demonstrated in several experimental models of status epilepticus. In primates, prolonged scizurcs inducc ncural damage despite maintenance of systemic metabolic parameters in the normal range (Meldrum et al., 1973). In rodents, intense electrographic seizure activity evoked by repeated frequent stimulation of the perforant path from the entorhinal cortex (EC) to dentate gyrus (DG) $(10 \mathrm{sec}$ of $20 \mathrm{~Hz}$ stimulation per minute for $24 \mathrm{hr}$ ) also induces damage to neurons in the hilus of the DG (Sloviter, 1983, 1987). In another rodent model, administration of kainic acid, an analog of the excitatory amino acid L-glutamate, induces intense acute seizure activity, which is accompanied by neuronal damage in CAl, CA3, the hilus of the DG, and other limbic structures (Nadler and Cuthbertson, 1980; Ben-Ari, 1985). Brief treatment with phenobarbital, which suppresses the acute seizure activity in this model, prevents excitotoxic neuronal damage in the hilus of the DG, reduces associated mossy fiber sprouting, and reduces enhanced susceptibility to evoked seizures (Sutula et al., 1992).

Although it is generally believed that brief sporadic seizures do not induce excitotoxic damage, human epilepsy is frequently associated with neuronal loss and gliosis in CA1, CA3, and the hilus of the DG. This pattern of neuronal loss, which may variably involve other hippocampal areas, is referred to as hippocampal sclerosis, Ammon's horn sclerosis, or mesial temporal sclerosis, and is the most common neuropathological finding in human temporal lobe epilepsy (Babb and Brown, 1987; Gloor, 1991). For over a century, there has been controversy about hippocampal sclerosis as a cause or effect of the repeated, brief seizures that are a feature of temporal lobe epilepsy (Babb and Brown, 1987; Sutula, 1990; Gloor, 1991).

The distribution of neuronal loss in human hippocampal sclerosis resembles the pattern of excitotoxic neuronal loss observed in models of status epilepticus (Sloviter and Damiano, 1981; Ben-Ari, 1985). It was of interest to determine whether repeated brief seizures, which are not accompanied by the systemic physiological and metabolic disturbances encountered in status epilepticus, might induce neuronal loss. In a previous study, we observed that brief seizures evoked by kindling, a model for the sporadic seizures that occur in human temporal lobe epilepsy (Goddard et al., 1969; McNamara, 1986), induced progressive neuronal loss in the hilus of the DG (Cavazos and Sutula, 1990). 
In the present study, we report that repeated kindled seizures induced progressive neuronal loss in the hippocampal formation in a pattern that closely resembles hippocampal sclerosis. Progressive neuronal loss was also observed in other limbic areas implicated in epilepsy, including the EC and endopyriform nucleus (EN), but was not detected in the somatoscnsory area of the neocortex.

Preliminary observations have appeared in abstract form (Cavazos and Sutula, 1991).

\section{Materials and Methods}

\section{Kindling and surgical procedures}

Sprague-Dawley male rats (250-350 gm) were anesthetized with pentobarbital $(60 \mathrm{mg} / \mathrm{kg}$, i.p.) and stereotaxically implanted with an insulated stainless steel bipolar electrode for stimulation and recording. The electrode was implanted in the perforant path near the region of the angular bundle $(8.1 \mathrm{~mm}$ posterior, $4.4 \mathrm{~mm}$ lateral, $3.5 \mathrm{~mm}$ ventral from bregma), in the amygdala $(1.5 \mathrm{~mm}$ posterior, $4.2 \mathrm{~mm}$ lateral, $8.8 \mathrm{~mm}$ ventral from bregma), or in the olfactory bulb ( $9 \mathrm{~mm}$ anterior, $1.2 \mathrm{~mm}$ lateral, $1.8 \mathrm{~mm}$ ventral from bregma). After a recovery period of 2 weeks, the unrestrained awake animals received twice daily kindling stimulation ( $5 \mathrm{~d}$ per week) with a $1 \mathrm{sec}$ train of $62 \mathrm{~Hz}$ biphasic constantcurrent $1.0 \mathrm{msec}$ square wave pulses. The stimulation was delivered at the lowest intensity that evoked an afterdischarge according to standard procedures (Cavazos et al., 1991). The electroencephalogram and afterdischarges were recorded from the bipolar electrode, which could be switched to the stimulator by a digital circuit for the delivery of the kindling stimulation. The evoked behavioral seizures were classified according to standard criteria (Racine, 1972; Sutula and Steward, 1986).

Rats received stimulation until three class $\mathrm{V}$ seizures were evoked. Another group received kindling stimulation until 30 class $V$ seizures were evoked. A third group received kindling stimulation until 150 class $\mathrm{V}$ seizures were evoked. Control groups were normal age-matched rats and unstimulated rats implanted with electrodes for 3 months.

\section{Histological procedures}

At least $18 \mathrm{hr}$ after the last seizure or after the period of control electrode implantation, the rats were deeply anesthetized and perfused transcardially with an aqueous solution of $10 \%(\mathrm{v} / \mathrm{v})$ formalin in $0.9 \%(\mathrm{w} / \mathrm{v})$ $\mathrm{NaCl}$ for 10-20 min. The brains were removed, postfixed for at least $10 \mathrm{~d}$ in same solution, dehydrated for $35 \mathrm{~d}$ in graded concentrations of alcohols, and then embedded in graded concentrations of low-viscosity nitrocellulose (celloidin) for $50 \mathrm{~d}$. Embedding in low-viscosity nitrocellulose provides superior preservation of the neuronal architecture, and is particularly suitable for quantitative studies (Konigsmark, 1969). Horizontal $20 \mu \mathrm{m}$ sections were cut using a sliding microtome from the surface of neocortex throughout the most ventral hippocampus. All sections were retained and stored in $70 \%$ ethanol. Every fifth section was stained with cresyl violet, but additional sections were also stained to ensure that equivalent areas were available for quantitative assessment in each specimen. In a pilot study, this histological method resulted in about $40 \%$ brain shrinkage compared to the volume calculated immediately after perfusion; the amount of tissue shrinkage with this method is comparable to previous studies (Amaral, 1978).

\section{Neuron counting procedures}

Locations for neuronal counting. Neuronal counts were obtained in the dentate gyrus (DG), hippocampus, entorhinal cortex (EC), the rostral endopyriform nucleus (EN), and somatosensory cortex (SSC) in horizontal sections at three standardized locations along the septotemporal (dorsoventral) axis of the hippocampal formation. The location of the regions assessed by stereological counting methods was identified by the following criteria.

(1) In a horizontal section about $800 \mu \mathrm{m}$ ventral from the most dorsal hippocampus (Fig. 1), neuronal density was measured in the hilus of the DG, the stratum granulosum of the DG, and the SSC. At this septotemporal level, the polymorphic neurons in the hilus of the DG are enclosed in an oval ring formed by granule cells in the stratum granulosum. The neuronal density in the hilus of the DG was determined at this location by quantitative counting methods in our previous report (Cavazos and Sutula, 1990).
(2) In a horizontal section about $1000 \mu \mathrm{m}$ ventral from the most dorsal hippocampus (Fig. 2), neuronal density was measured in the stratum pyramidale of the hippocampus proper (CA3c, CA3a, CA2, $\mathrm{CA} 1 \mathrm{c}$, and CAla), layers 2 and 6 of the medial EC (MEC2, MEC6) and layers 2 and 6 of the lateral EC (LEC2, LEC6). At this septotemporal level, pyramidal neurons in CA $3 \mathrm{c}$ are partially enclosed by granule cells in the stratum granulosum.

(3) In a horizontal section about $2800 \mu \mathrm{m}$ ventral from the most dorsal hippocampus that included the motor nuclei of cranial nerves III and IV (Fig. 3), neuronal density was measured in the hilus of the DG, the stratum pyramidale of the hippocampus proper (CA3c, CA3a, $\mathrm{CA} 2, \mathrm{CA} 1 \mathrm{c}$, and CA1 a), layers 2 and 6 of the medial EC (MEC2, MEC6), layers 2 and 6 of the lateral EC (LEC2, LEC6), the stratum granulosum of the DG, and the rostral EN. In a few brains that were sectioned at a slight angle to the true horizontal plane, the EN was not present in this standardized section, as the EN is quite anterior to the motor nuclei of cranial nerves III, IV, and ventral hippocampus. In these cases, it was necessary to select a more ventral section to measure appropriately the neuronal density of the EN.

Quantitative counting methods. Accurate neuronal counting may be difficult due to errors introduced by double counting of neurons cut at the edges of sections, or systematic changes in tissue volume. Although stereological theory suggests that the most accurate neuronal densities can be obtained by counting nuclcoli (Konigsmark, 1969), previous studies have revealed that approximately $40 \%$ of polymorphic neurons in the hilus of the DG in the rat contain multiple nucleoli (Cavazos and Sutula, 1990). As counting nucleoli would thus result in falsely high neuronal densities, neurons were counted only if the nucleus could be identified in the section. Nuclear counts were obtained ipsilateral and contralateral to the stimulating electrode at the standardized locations identified by the criteria described in the previous paragraph, by manual counting with an eyepiece reticule $\left(25 \mathrm{~mm}^{2}\right)$. The investigator performing the counts was unaware of the identity of the sections, and the order of examination of the sections was randomized. In each reticule field, nuclei that overlapped the lower and left edges of the reticule were counted, but nuclei that overlapped the upper and right edges were not counted. In each location, the number of neurons and their relative position were recorded using a camera lucida, and were summed to obtain the nuclear count per reticule field. The magnification selected to obtain the nuclear count per reticule field at each location was selected to include 10-40 neurons as listed in Table 1 . In the hilus and stratum granulosum of the DG, and the rostral EN, two reticule fields were selected for each ipsilateral and contralateral location as indicated in Figures 1 and 3 . In pilot experiments, the nuclear counting procedure in this study had an interobserver variability of less than $10 \%$; the intraobserver variability was 3\% (Cavazos and Sutula, 1990). Previous studies have revealed that these methods are quite sensitive for assessment of neuronal loss, which typically exceeds $15-20 \%$ before a lesion is reliably detected by visual inspection (Konigsmark, 1969; Cavazos and Sutula, 1990).

Mean neuronal density $\left(N_{i}\right)$ for each counted region was calculated from the average nuclear count per reticule field $\left(n_{i}\right)$ obtained from the septal and temporal sections as defined in Figures 1-3, according to the Floderus formula: $N_{i}=n_{i} * t /(t+d-2 b)$, where $N_{i}$ is the corrected neuronal density, $n$ is the average nuclear count per reticule field, $t$ is the section thickness, $d$ is the average nuclear diameter at each of the counted regions, and $b$ is a constant that represents the limit of optical resolution for each objective (Konigsmark, 1969; Cavazos and Sutula, 1990). For this study, the constant $b$ for each objective was as follows: $20 \times$ (NA. 0.75), $b=0.36 \mu \mathrm{m} ; 40 \times($ NA 0.95$), b=0.28 \mu \mathrm{m} ; 100 \times$ oil immersion (NA 0.19), $b=0.19 \mu \mathrm{m}$ (Konigsmark, 1969). For each section, the thickness $(t)$ of each section was also determined by measuring the distance between upper and lower focal planes of the section with the stage micrometer using the $100 \times$ oil-immersion objective. The average nuclear diameter $(d)$ for each cell population is provided in Table 1 . As the ratio of section thickness $(t)$ to nuclear diameter $(d)$ was always above 1.5 (range, 1.82-3.10), the stereological assumptions of this method are valid (Clarke, 1992).

Volume measurements. As systematic changes in tissue volume could alter the neuronal density, estimates of the volume of the hippocampal region (hippocampus proper, subiculum, and DG) were obtained ipsilateral and contralateral to the stimulating electrode using a stereological approximation method (West et al., 1978; Cavazos and Sutula, 1990). The volume was estimated by measuring the area of the hippocampal region of four horizontal sections $(1000,2000,3000$, and $4000 \mu \mathrm{m}$ ventral to the most dorsal hippocampal section) using an image analysis 


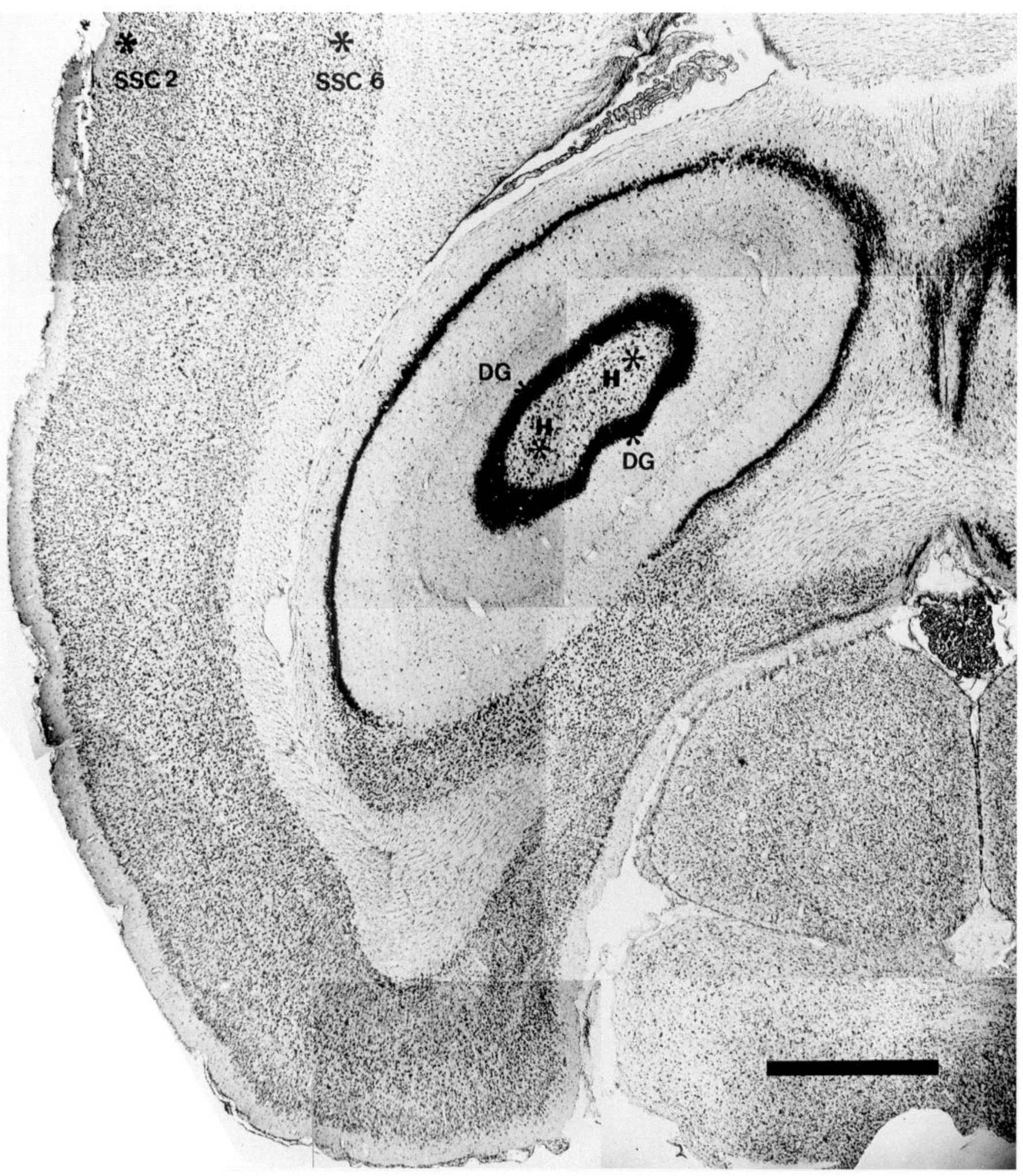

Figure 1. Representative horizontal cresyl violet-stained section of the dorsal hippocampal formation and adjacent cortex of a normal rat about $800 \mu \mathrm{m}$ ventral from the most dorsal hippocampus. At this septotemporal level, the polymorphic neurons in the hilus of the DG are enclosed in an oval ring formed by granule cells in the stratum granulosum. Neuronal density was measured at this location in the hilus of the DG, the stratum granulosum of the DG, and in layers 2 and 6 of the SSC, at sites indicated by the asterisks. $H$, hilus of the DG; DG, stratum granulosum of the DG; SSC 2, layer 2 of the somatosensory cortex; SSC 6, layer 6 of the somatosensory cortex. Scale bar, $1000 \mu \mathrm{m}$. 


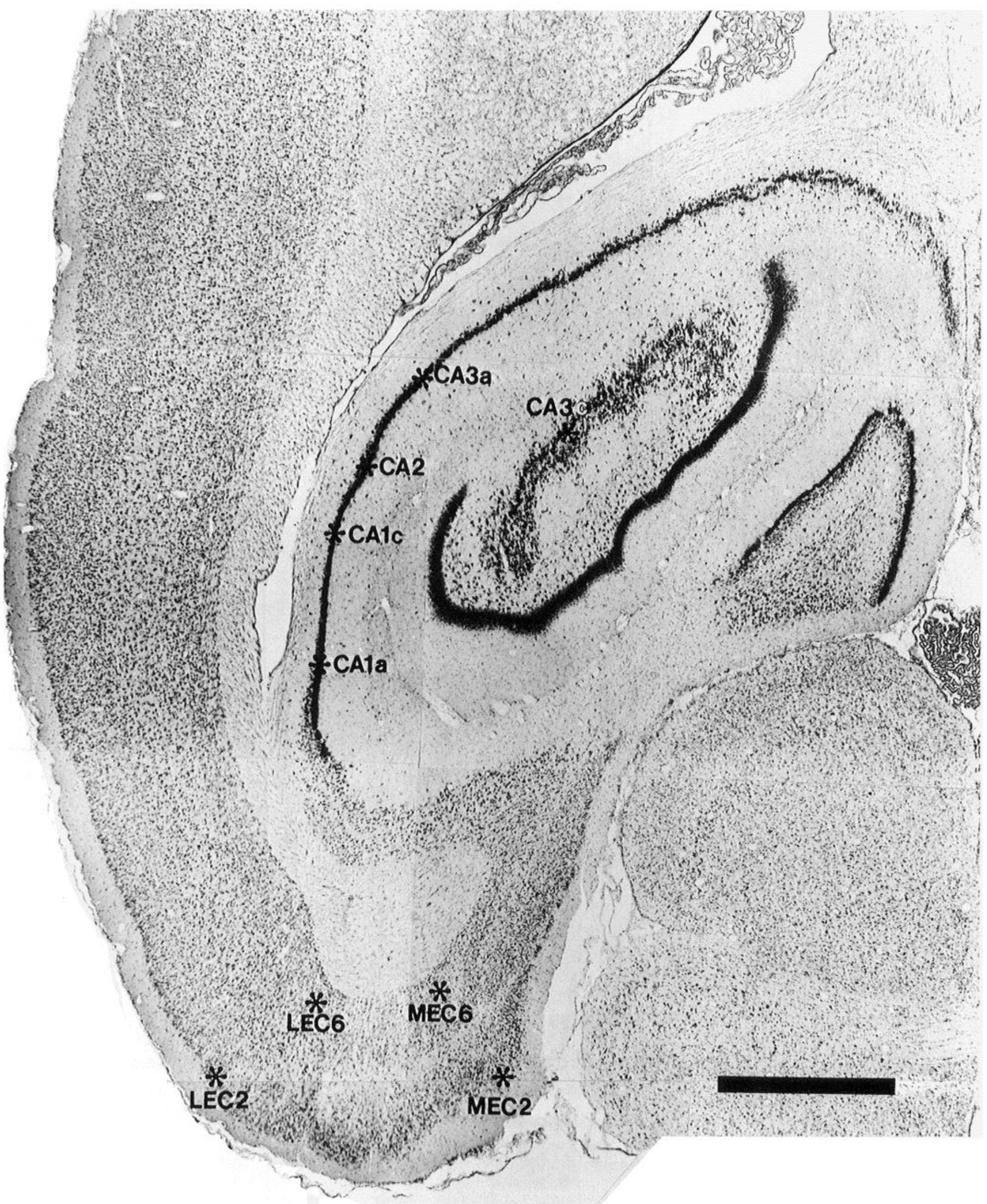

Figure 2. Representative horizontal cresyl violet-stained section of the dorsal hippocampal formation and adjacent cortex of a normal rat about $1000 \mu \mathrm{m}$ ventral from the most dorsal hippocampus. At this septotemporal level, pyramidal neurons in CA3c are partially enclosed by granule cells in the stratum granulosum. Neuronal density was measured at this location in CA3c, CA3a, CA2, CA1c, CA1a, and layers 2 and 6 of both the medial and lateral EC, at sites indicated by the asterisks. $M E C 2$, layer 2 of the medial entorhinal cortex; $M E C 6$, layer 6 of the medial entorhinal cortex; $L E C 2$, layer 2 of the lateral entorhinal cortex; $L E C 6$, layer 6 of the lateral entorhinal cortex. Scale bar, $1000 \mu \mathrm{m}$. 

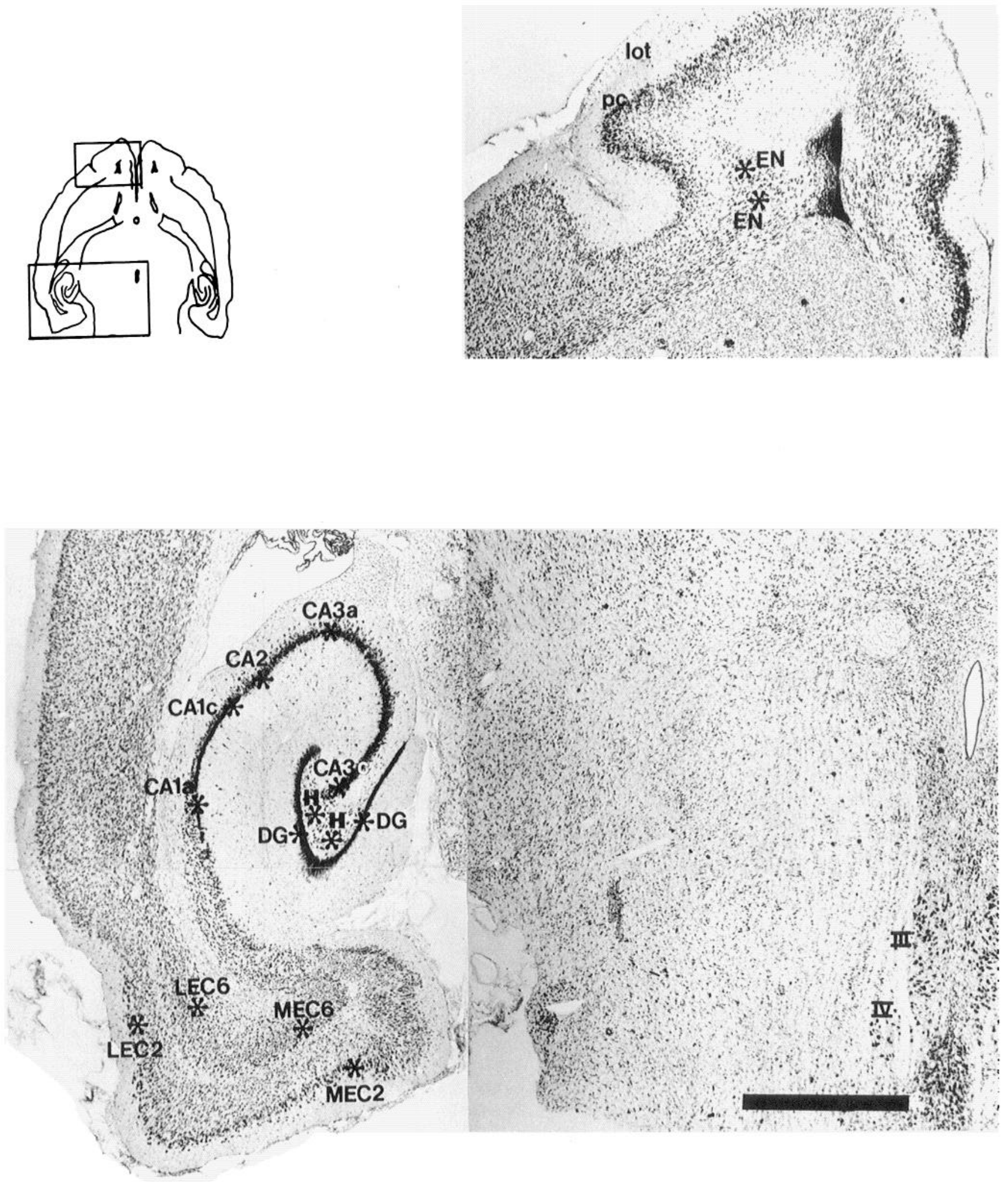

Figure 3. Representative horizontal cresyl violet-stained sections of the ventral hippocampal formation, adjacent cortex, and the region of the rostral EN of a normal rat about $3600 \mu \mathrm{m}$ ventral from the most dorsal hippocampus. The orientation of the two photomicrographs is indicated in the schematic diagram at the upper left. At this level the motor nuclei of cranial nerves III and IV are present. Neuronal density was measured in the hilus of the DG, the stratum pyramidale of CA3c, CA3a, CA2, CAlc, and CA1a, layers 2 and 6 of both the medial and lateral EC, the stratum granulosum of the DG, and the region of the rostral EN, at sites indicated by the asterisks. EN, endopyriform nucleus; lot, lateral olfactory tract; $p c$, pyriform cortex; $I I I$, nucleus of cranial $\mathrm{n}$. III; $I V$, nucleus of cranial $\mathrm{n}$. IV; other abbreviations are as in Figures 1 and 2 . Scale bar, $1000 \mu \mathrm{m}$. 


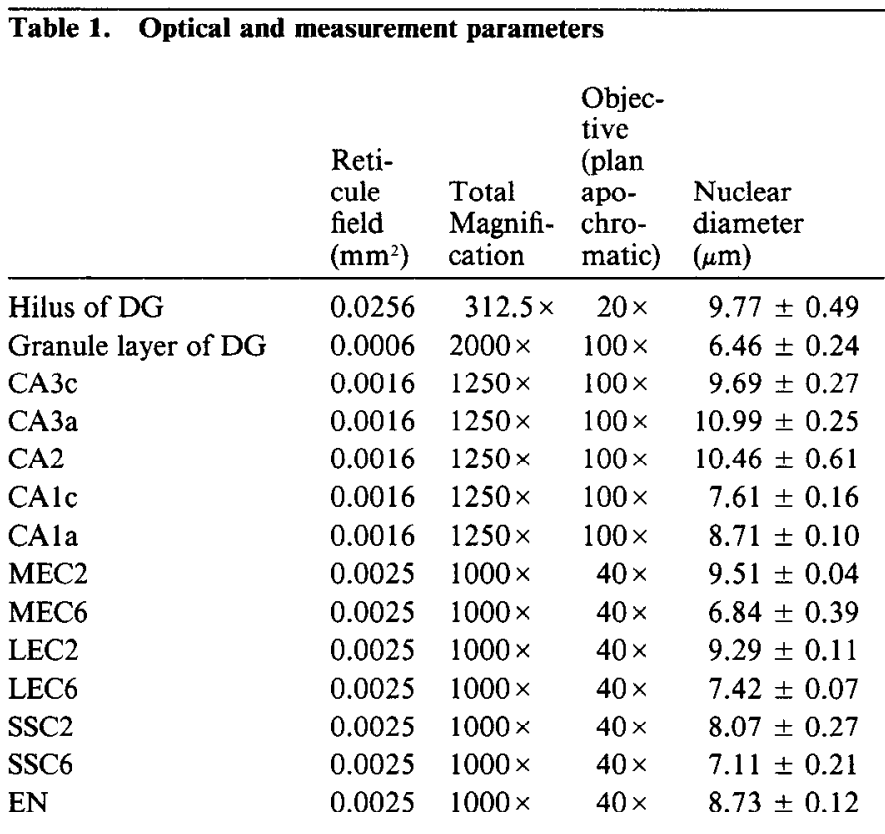

system. The formula $V=\left(A_{n}+A_{n+1}\right) t / 2$ was used to estimate the volume between the sections, where $V$ is the volume, $A_{n}$ is the area of the hippocampal region at a given level, $A_{n+1}$ is the area at the next level, and $t$ is the distance between the two levels (West et al., 1978). For each rat, the mean neuronal density $\left(N_{i}\right)$ at each location in the hippocampal formation was calculated according to the formula $N_{r}=N_{i} * V_{x} / V_{c}$, where $V_{x}$ is the estimated hippocampal volume of the given rat, and $V_{c}$ is the estimated mean hippocampal volume of control rats (Cavazos and $\mathrm{Su}$ tula, 1990).

Statistical methods. The differences in nuclear counts per reticule field $\left(n_{i}\right)$, mean neuronal densities $\left(N_{i}\right)$, and volume-corrected neuronal densities $\left(N_{v}\right)$ for each region were statistically analyzed using a general linear model for multiway analysis of variance (GLM-ANOVA, split plot). Confidence intervals were calculated for each of the significant variables (i.e., number of class V seizures) using a one-way ANOVA (Tukey's multiple comparison method), and were considered significant when $p<0.05$. All measures reported in this study are expressed as mean \pm SEM.

\section{Results}

Neuronal densities $\left(N_{i}\right)$ were calculated from the average nuclear counts $\left(n_{i}\right)$ in 12 control rats and a total of 20 rats that experienced 3,30 , or 150 class $V$ seizures evoked by kindling. As the differences in neuronal density as a function of the site of stimulation were not significant ( $p=0.42$, one-way ANOVA), rats stimulated in the perforant path, amygdala, or olfactory bulb were combined for further analysis. The group of rats with three class $\mathrm{V}$ seizures $(N=5)$ included four rats that received stimulation in the perforant path and one rat stimulated in the amygdala. The group with 30 class $V$ seizures $(N=6)$ included five rats that received stimulation in the perforant path and one rat stimulated in the amygdala. The group of rats with 150 class V seizures $(N=9)$ included three rats that received stimulation in the perforant path, three rats stimulated in the amygdala, and three rats stimulated in the olfactory bulb. The overall results were not changed if statistical analysis was restricted to rats that received only perforant path stimulation.

\section{Calculated hippocampal volume}

The average hippocampal volume of control rats was $20.9 \pm$ $0.6 \mathrm{~mm}^{3}$. For the group of rats that experienced three class $\mathrm{V}$ $m \alpha=\infty$ क $\dot{0} \dot{0} \dot{0} \dot{0} \dot{0} \dot{-i}$ $+1+1+1+1+1+1+1+1$ $m=888 m \tilde{ก}$

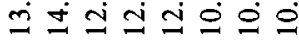

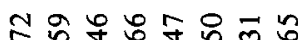
○ं $+1+1+1+1+1+1+1+1$ 꾱요음

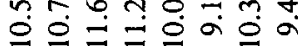

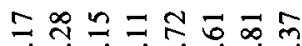

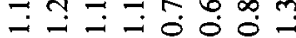
$+1+1+1+1+1+1+1+1$ 은 용요으응 ஸ்

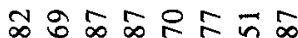
$\dot{0} 0 \stackrel{0}{0} \dot{0} 0 \dot{0} 0 \dot{0}-\dot{0}$ H $8 \curvearrowleft$

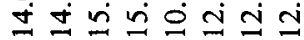

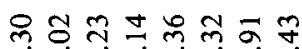

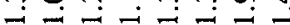
$+1+1+1+1+1+1+1+1$ 응응요워ำ

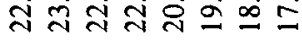

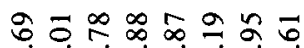

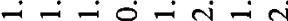
$+1+1+1+1+1+1+1+1$ 충요유

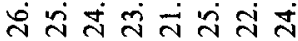

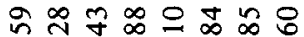

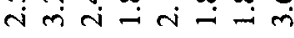
$+1+1+1+1+1+1+1+1$

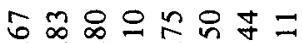

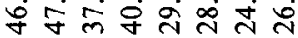

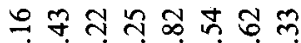
i$+1+1+1+1+1+1+1+1$ 용ㅇㅇ은요

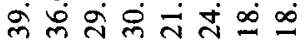

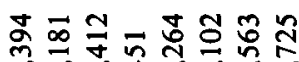
a 00 $+1+1+1+1+1+1+1+1$

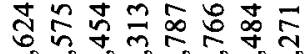

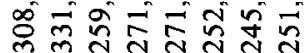

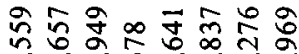

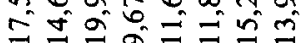
$+1+1+1+1+1+1+1$ 형 $\frac{1}{8} \sigma \stackrel{2}{2} \infty$

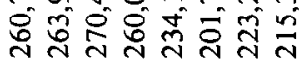

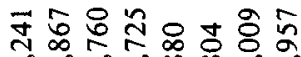

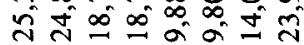
$+1+1+1+1+1+1+1$

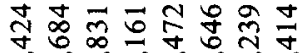
ஸి

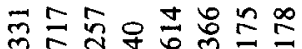
ปे H $11+1+1+1+1+1$

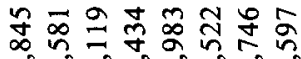
迥命尽官

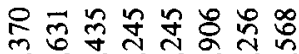
की $+1+1+1+1+1+1+1+1$

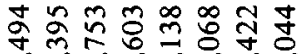

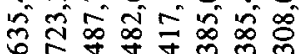
$\underline{-}=-v_{n}=$ ชㅇㅇㅇㅇㅇ유유

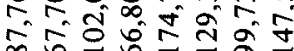
$+1+1+1+1+1+1+1+1$

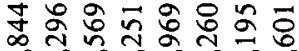

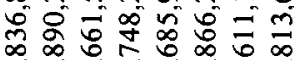
$\infty \infty$

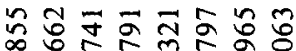
舟吉寽 $+1+1+1+1+1+1+1$ 少

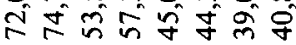

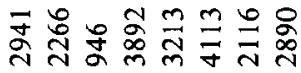
$+1+1+1+1+1+1+1$

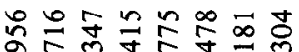
की 중

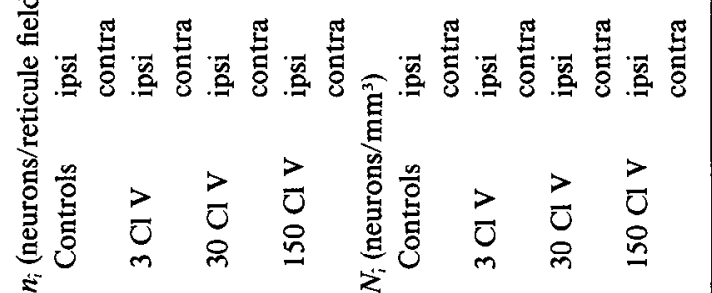




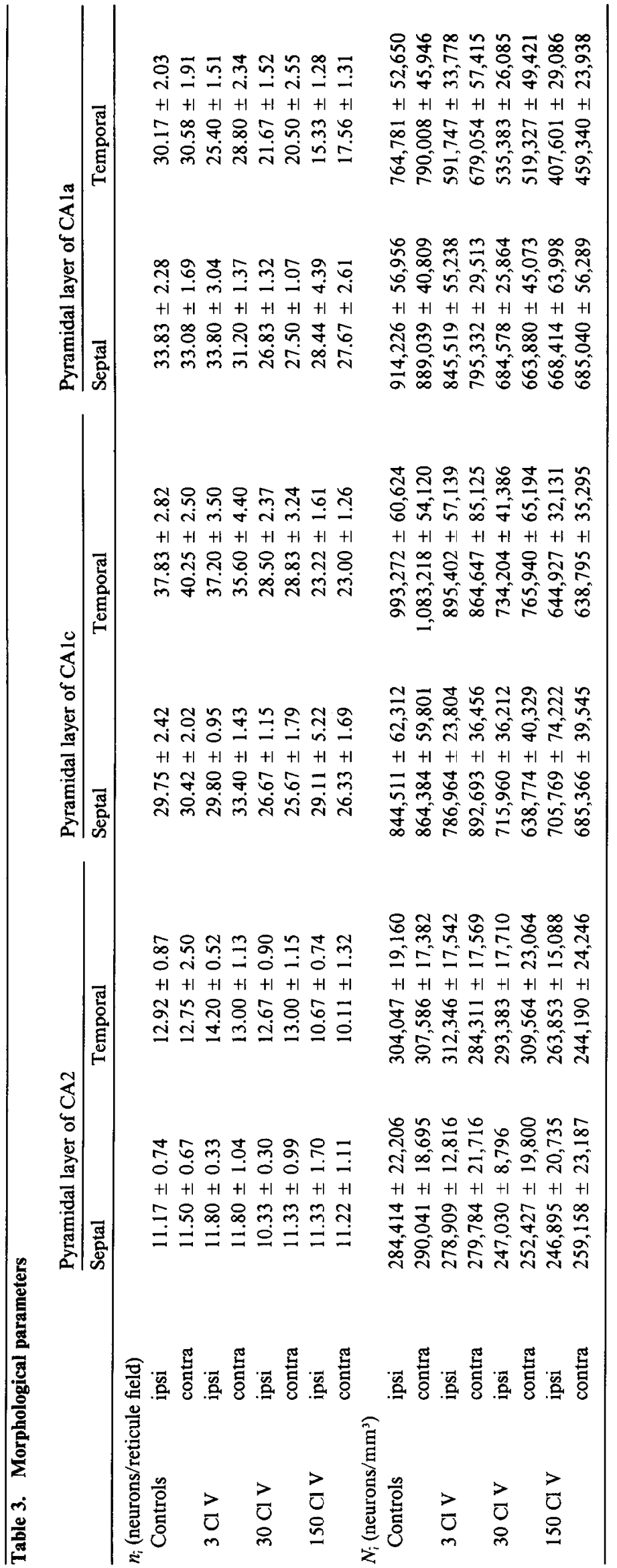

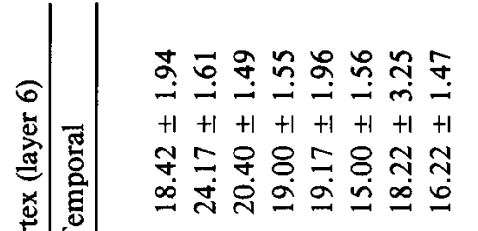

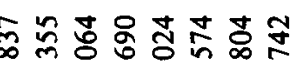

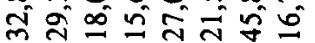
$+1+1+1+1+1+1+1+1$

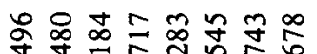

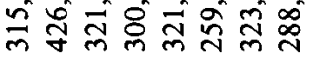

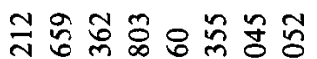

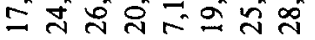
$+1+1+1+1+1+1+1+1$

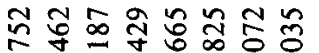

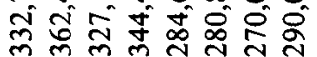

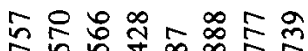

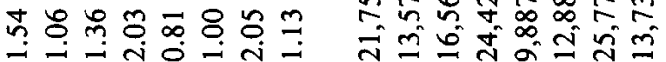
$+1+1+1+1+1+1+1$ 정융ㅇㅇㅇㅇ $\dot{9} \dot{\square} \dot{0} 00$

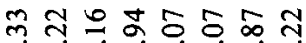
- i i i $+1+1+1+1+1+1+1+1$

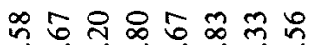

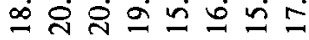

\& $m-m-m$ n n N $+1+1+1+1+1+1+1$ m

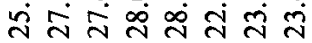

ติธ - तo $+1+1+1+1+1+1+1+1$

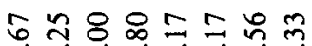
유추

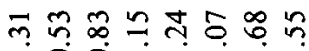
- $000-2-1$ $+1+1+1+1+1+1+1+1$ 용ㅇㅇ으을

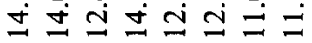

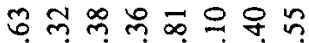
$+1+1+1+1+H+1+1+1$ 흥ㅇㅇㅇㅢ

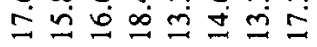
$+1+1+1+1+1+1+1+1$

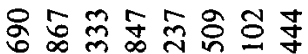

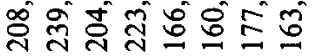

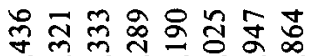

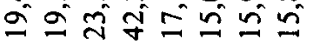
$+1+1+1+1+1+1+1+1$

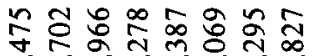

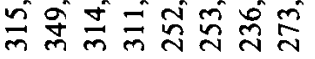

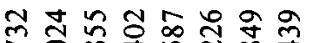

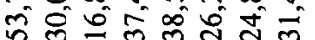
$+1+1+1+1+1+1+1$

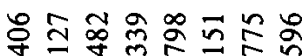

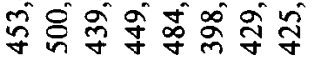

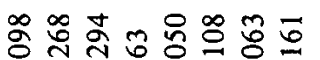

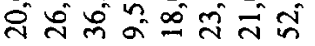
$+1+1+1+1+1+1+1+1$

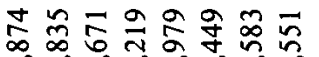

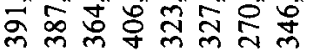

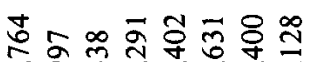
ते $+1+1+1+1+1+1+1+1$

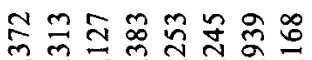

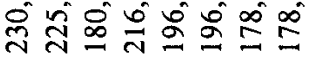

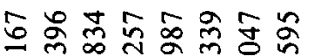

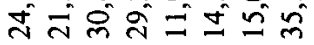
$+1+1+1+1+1+1+1+1$

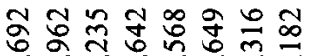

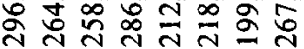
흘

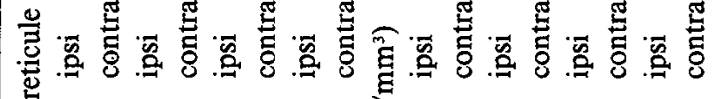

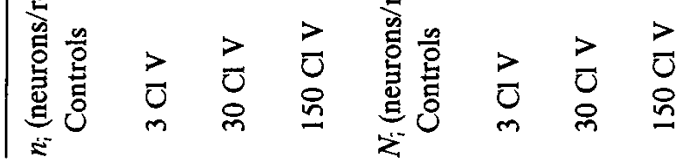




\begin{tabular}{|c|c|c|c|c|}
\hline & & \multirow{2}{*}{$\begin{array}{l}\text { Endopyriform } \\
\text { nucleus }\end{array}$} & \multicolumn{2}{|c|}{ Somatosensory cortex } \\
\hline & & & Layer 2 & Layer 6 \\
\hline \multicolumn{5}{|c|}{$n_{i}$ (neurons/reticule field) } \\
\hline \multirow[t]{2}{*}{ Controls } & ipsi & $11.96 \pm 0.55$ & $13.58 \pm 0.69$ & $16.67 \pm 1.83$ \\
\hline & contra & $12.00 \pm 0.55$ & $14.42 \pm 0.49$ & $16.42 \pm 0.59$ \\
\hline \multirow[t]{2}{*}{$3 \mathrm{Cl} \mathrm{V}$} & ipsi & $11.80 \pm 0.36$ & $14.60 \pm 1.31$ & $17.40 \pm 1.22$ \\
\hline & contra & $11.70 \pm 0.64$ & $15.80 \pm 1.25$ & $16.20 \pm 0.91$ \\
\hline \multirow[t]{2}{*}{$30 \mathrm{Cl} \mathrm{V}$} & ipsi & $9.83 \pm 0.63$ & $13.67 \pm 0.90$ & $14.67 \pm 1.22$ \\
\hline & contra & $9.25 \pm 0.56$ & $14.17 \pm 0.64$ & $14.67 \pm 0.45$ \\
\hline \multirow[t]{2}{*}{$150 \mathrm{Cl} \mathrm{V}$} & ipsi & $9.22 \pm 1.50$ & $15.11 \pm 1.70$ & $17.22 \pm 1.73$ \\
\hline & contra & $9.50 \pm 1.24$ & $14.33 \pm 1.89$ & $15.33 \pm 1.54$ \\
\hline \multicolumn{5}{|c|}{$N_{i}$ (neurons $/ \mathrm{mm}^{3}$ ) } \\
\hline \multirow[t]{2}{*}{ Controls } & ipsi & $196,442 \pm 10,128$ & $219,265 \pm 7,738$ & $278,065 \pm 24,701$ \\
\hline & contra & $198,820 \pm 8,608$ & $246,503 \pm 8,170$ & $292,723 \pm 10,361$ \\
\hline \multirow[t]{2}{*}{$3 \mathrm{Cl} \mathrm{V}$} & ipsi & $180,157 \pm 5,951$ & $228,124 \pm 10,865$ & $284,549 \pm 13,160$ \\
\hline & contra & $178,621 \pm 8,684$ & $274,477 \pm 19,528$ & $294,098 \pm 13,281$ \\
\hline \multirow[t]{2}{*}{$30 \mathrm{Cl} \mathrm{V}$} & ipsi & $157,601 \pm 7,809$ & $246,578 \pm 24,276$ & $279,686 \pm 37,125$ \\
\hline & contra & $154,106 \pm 8,572$ & $246,843 \pm 12,121$ & $266,129 \pm 6,033$ \\
\hline \multirow[t]{2}{*}{$150 \mathrm{Cl} \mathrm{V}$} & ipsi & $151,986 \pm 19,877$ & $256,898 \pm 22,053$ & $305,784 \pm 23,463$ \\
\hline & contra & $156,409 \pm 16,952$ & $251,738 \pm 26,173$ & $286,033 \pm 26,901$ \\
\hline
\end{tabular}

seizures, the average hippocampal volume was $21.3 \pm 1.0 \mathrm{~mm}^{3}$. For the group that experienced 30 class $\mathrm{V}$ seizures, the average hippocampal volume was $22.1 \pm 0.8 \mathrm{~mm}^{3}$. After 150 class $\mathrm{V}$ seizures, the average hippocampal volume was $22.6 \pm 1.5 \mathrm{~mm}^{3}$. Although there was a small increase in the calculated hippocampal volumes of these kindled rats perfused at $18 \mathrm{hr}$ after the last seizure, this trend did not achieve statistical significance ( $p$ $=0.58$, one-way ANOVA). As the results using volume-corrected neuronal densities $\left(N_{r}\right)$ did not differ significantly from the results using $N_{i}$, the overall analysis was performed using $n_{i}$ and $N_{i}$. The morphological parameters $n_{i}$ and $N_{i}$ are provided in Tables 2-5.

\section{Septotemporal variation of neuronal densities $\left(\mathrm{N}_{\mathrm{i}}\right)$ in normal rats}

In agreement with previous studies (Amaral et al., 1990), there were differences in the neuronal densities of limbic structures along the septotemporal axis of the hippocampal formation in normal rats (for a summary, see Table 6). In normal rats, the neuronal densities in the hilus of the DG, CA3a, and MEC6 were significantly higher in the temporal pole than in the septal pole. In contrast, the neuronal densities of CA1a, MEC2, and LEC2 were higher in the septal pole than in the temporal pole.
Significant differences in neuronal density along the septotemporal axis were not noted in $\mathrm{CA} 3 \mathrm{c}, \mathrm{CA} 1 \mathrm{c}, \mathrm{CA} 2$, the granule cell layer of the DG, or LEC6.

\section{Decreases in neuronal density $\left(\mathrm{N}_{\mathrm{i}}\right)$ as a function of evoked seizures}

There were progressive decreases in neuronal density in a variety of limbic structures as a function of increasing numbers of evoked seizures. With increasing numbers of evoked seizures, the neuronal densities $\left(N_{i}\right)$ progressively decreased in the polymorphic region of the hilus of the DG, CA1c, CA1a, CA3c, CA3a, the stratum granulosum of the DG, CA2, MEC2, MEC6, LEC2, LEC6, and the rostral EN. Alterations in $n_{i}$ and $N_{i}$ were not observed in layer 2 or layer 6 of the SSC (for a summary, see Table 7, Fig. 4).

Neuronal loss after three class $V$ seizures. The reduction in $n_{i}$ and $N_{i}$ was not equivalent in all locations ( $p<0.001$, GLMANOVA; see Table 7, Fig. 4). After three class V seizures, there were significant reductions in $N_{i}$, expressed as percentage of the control value, in the septal (dorsal) pole of the hilus of the DG $(78 \%)$, the temporal hilus of the DG $(76 \%)$, temporal CAla $(82 \%)$, and temporal CA3a $(83 \%)$.

Table 6. Septotemporal variation of neuronal densities in normal rats

\begin{tabular}{lccl}
\multicolumn{2}{l}{ Neurons $/ \mathrm{mm}^{3}( \pm \mathrm{SEM})$} & \\
\cline { 2 - 3 } \multicolumn{2}{l}{ Septal } & Temporal & \\
\hline Hilus DG & $58,956 \pm 2,941$ & $72,098 \pm 4,855$ & $F=28.59, p<0.0001$ \\
CA3a & $260,717 \pm 17,559$ & $308,624 \pm 19,394$ & $F=10.84, p<0.001$ \\
MEC6 & $391,874 \pm 20,098$ & $453,406 \pm 53,732$ & $F=30.67, p<0.0001$ \\
CA1a & $914,226 \pm 56,956$ & $764,781 \pm 52,650$ & $F=38.55, p<0.0001$ \\
MEC2 & $296,692 \pm 24,167$ & $230,372 \pm 22,764$ & $F=17.28, p<0.0005$ \\
LEC2 & $315,475 \pm 19,436$ & $208,690 \pm 21,757$ & $F=74.03, p<0.0001$ \\
\hline
\end{tabular}




\begin{tabular}{|c|c|c|c|c|c|}
\hline & & $\begin{array}{l}\text { Num } \\
\text { class }\end{array}$ & $\begin{array}{l}\text { er of } \\
\text { seizu }\end{array}$ & & \\
\hline & & 3 & 30 & 150 & \\
\hline DG hilus & (s) & $78 \%$ & $63 \%$ & $51 \%$ & $F=60.75, p<0.0001$ \\
\hline & (t) & $76 \%$ & $61 \%$ & $54 \%$ & \\
\hline CAla & (s) & - & $75 \%$ & $75 \%$ & $F=29.39, p<0.0001$ \\
\hline & (t) & $82 \%$ & $68 \%$ & $56 \%$ & \\
\hline CA3a & (s) & - & $83 \%$ & $84 \%$ & $F=9.46, \quad p<0.0005$ \\
\hline & (t) & $83 \%$ & $82 \%$ & $78 \%$ & \\
\hline CAlc & (s) & - & $79 \%$ & $81 \%$ & $F=20.99, p<0.0001$ \\
\hline & $(\mathfrak{t})$ & - & $72 \%$ & $62 \%$ & \\
\hline $\mathrm{CA} 3 \mathrm{c}$ & (s) & - & $73 \%$ & $77 \%$ & $F=18.82, p<0.0001$ \\
\hline & $(\mathrm{t})$ & - & $74 \%$ & $71 \%$ & \\
\hline $\mathrm{CA} 2$ & (s) & - & - & - & $F=3.38, \quad p<0.03$ \\
\hline & (t) & - & - & $83 \%$ & \\
\hline DG sg & (s) & - & - & - & $F=5.16, \quad p<0.006$ \\
\hline & (t) & - & $83 \%$ & $80 \%$ & \\
\hline MEC2 & (s) & - & $77 \%$ & $83 \%$ & $F=4.35, \quad p<0.011$ \\
\hline & (t) & - & $86 \%$ & $78 \%$ & \\
\hline LEC2 & (s) & - & $76 \%$ & $77 \%$ & $F=14.62, p<0.0005$ \\
\hline & (t) & - & $73 \%$ & $76 \%$ & \\
\hline MEC6 & (s) & - & - & $79 \%$ & $F=4.73, \quad p<0.008$ \\
\hline & (t) & - & - & $90 \%$ & \\
\hline LEC6 & (s) & - & - & $81 \%$ & $F=8.03, \quad p<0.001$ \\
\hline & $(t)$ & - & $78 \%$ & $83 \%$ & \\
\hline EN & & - & $79 \%$ & $78 \%$ & $F=5.21, \quad p<0.005$ \\
\hline $\mathrm{SSC} 2, \mathrm{SSC} 6$ & & - & - & - & \\
\hline
\end{tabular}

s, septal; $t$, temporal; DG, dentate gyrus; DG sg, granule cell layer of the dentate gyrus; MEC2, MEC6, layers 2, 6 of medial entorhinal cortex; LEC2, LEC6, layers 2,6 of lateral entorhinal cortex; EN, endopyriform cortex; SSC2, SSC6, layers 2, 6 of somatosensory cortex.

Neuronal loss after 30 class $V$ seizures. After 30 class $V$ seizures, there were significant reductions in $N_{i}$ in the septal hilus of the DG (63\% of the control value), CA3c (73\%), CA3a (83\%), CAlc (79\%), CAla (75\%), MEC2 (77\%), and LEC2 (76\%). In the temporal location, there were significant reductions in $N_{i}$ in the hilus of the DG (61\% of the control value), the stratum granulosum of the DG (83\%), CA3c (74\%), CA3a (82\%), CA1c (72\%), CAla (68\%), MEC2 (86\%), LEC2 (73\%), LEC6 (78\%), and the rostral EN (79\%). After 30 class $V$ seizures, the neuronal densities in the hilus of the DG and the pyramidal layer of CA3c and CAlc were significantly different from the neuronal densities in these locations after three class $\mathrm{V}$ seizures (one-way ANOVA, $p<0.05$ ).

Neuronal loss after 150 class $V$ seizures. After 150 class V seizures, there were significant reductions in $N_{i}$ in the septal location of the hilus of the DG $(51 \%$ of the control value; Fig. $5 A, B)$, MEC6 (79\%), and LEC6 (81\%). In the temporal location, there were significant reductions in $N_{i}$ in the hilus of the DG ( $54 \%$ of control value; Fig. $5 C, D)$, the stratum granulosum of the DG $(80 \%)$, CA3c $(71 \%)$, CA3a (78\%), CA2 (83\%), CAlc (62\%; Fig. 6), CAla (56\%; Fig. 7), MEC2 (78\%), MEC6 (90\%), and the rostral $\mathrm{EN}(78 \%)$. After 150 class $\mathrm{V}$ seizures, the neuronal density in the hilus of the DG, CA3c, CA1c, and CA1a was significantly different from the neuronal density in these locations after three class $V$ seizures (one-way ANOVA, $p<$ 0.05 ). These results indicated that neuronal loss in these locations was progressive as a function of the number of seizures.
There were no significant differences between the neuronal densities obtained ipsilateral and contralateral to the stimulating electrode (Tables $2-5 ; p=0.46$, GLM-ANOVA). The general results are summarized in Figure 4.

\section{Septotemporal variations in seizure-induced neuronal loss}

The decreases in neuronal densities tended to be greater in the temporal pole than in the septal pole, as indicated by the ratio of septal to temporal neuronal density in DG, CAlc, and CAla. The ratio of septal:temporal neuronal densities in CA1c significantly increased as a function of the number of seizures $(p<$ $0.028, F=3.42$, GLM-ANOVA; Table 3, Fig. 6). This finding suggested that the temporal pole of $\mathrm{C} \Lambda 1 \mathrm{c}$ was more vulnerablc to seizure-induced neuronal loss than the septal pole.

\section{Discussion}

In this experiment, progressive decreases in neuronal density were observed in the DG, hippocampus, EC, and rostral EN after repeated brief kindled seizures. As there were no significant changes in tissue volume or differential shrinkage in control and kindled rats, the decreases in neuronal density most likely reflect neuronal loss induced by the repeated brief kindled seizures.

Many previous studies have not detected neuronal loss or structural lesions as a consequence of repeated brief kindled seizures (Goddard et al., 1969; Crandall et al., 1979; Sutula et al., 1988; Represa et al., 1989; Bertram and Lothman, 1993). However, many of these studies did not employ histological and quantitative stereological techniques that enabled reliable detection of neuronal loss, or evaluated neuronal populations after only three class $\mathrm{V}$ seizures, when significant seizure-induced neuronal loss first becomes detectable by the methods employed in this study. The results of this study do not exclude the possibility that more subtle neuronal loss might be detected by more sensitive methods after only a few evoked seizures, or a single scizurc.

These experiments demonstrated that repeated electrical stimulation that evoked kindled seizures in limbic pathways was sufficient to induce neuronal loss in a variety of limbic areas. It seems likely that the neuronal loss was the result of seizures rather than damage caused by direct effects of stimulation, as there was approximately equal neuronal loss ipsilateral and contralateral to the stimulating electrode in all regions selected for study. In support of this conclusion, previous studies have also demonstrated that kindled seizures rapidly activate hippocampal pathways bilaterally (Stringer and Lothman, 1992), perhaps by the prominent commissural pathways which are a feature of the Sprague-Dawley rat.

\section{Selective vulnerability of limbic structures to seizure-induced neuronal loss}

There were progressive seizure-induced decreases in the neuronal density of a variety of limbic structures, but the neuronal density of the SSC was not altered by as many as 150 seizures. These results demonstrated that the quantitative stereological methods of this study were not merely detecting a diffuse or global effect of repeated seizures on central neurons, but rather a specific vulnerability of certain neuronal populations to seizure-induced damage. In particular, there appears to be significant vulnerability of the neuronal populations in limbic structures such as the DG, hippocampus, F.C, and rostral EN.

The present study extended our previous observations about the progressive loss of polymorphic neurons in the hilus of the 
HILUS OF THE DENTATE GYRUS

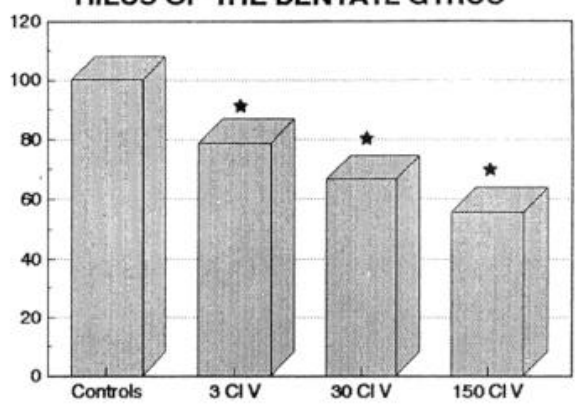

PYRAMIDAL LAYER OF CA2

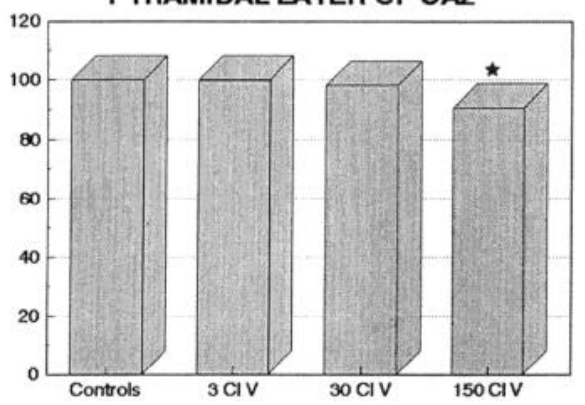

MEDIAL ENTORHINAL CORTEX

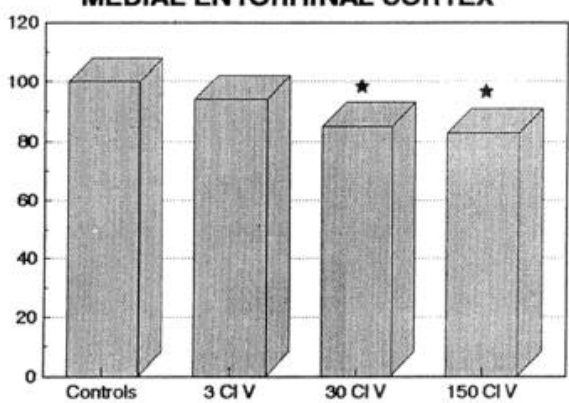

DENTATE GRANULE LAYER

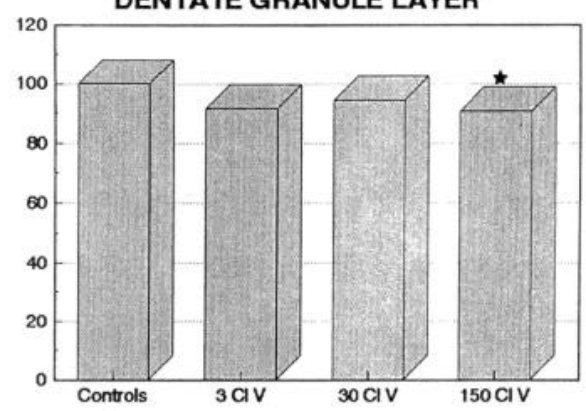

PYRAMIDAL LAYER OF CA1

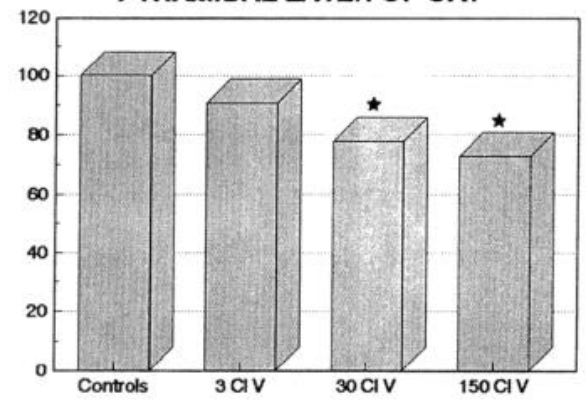

LATERAL ENTORHINAL CORTEX

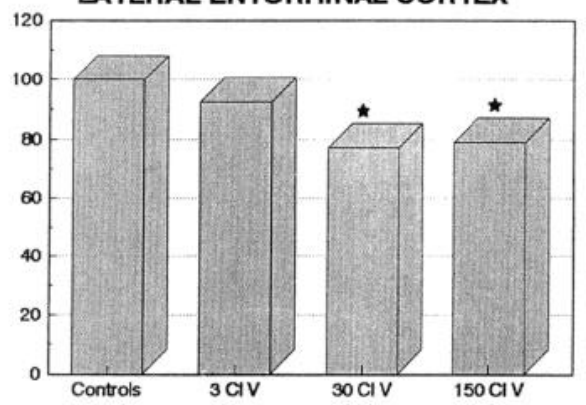

PYRAMIDAL LAYER OF CA3

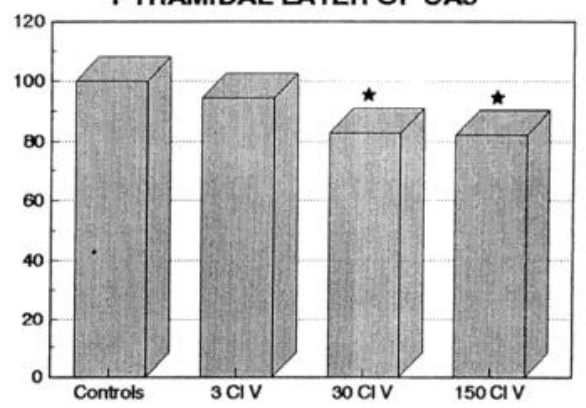

ENDOPYRIFORM NUCLEUS

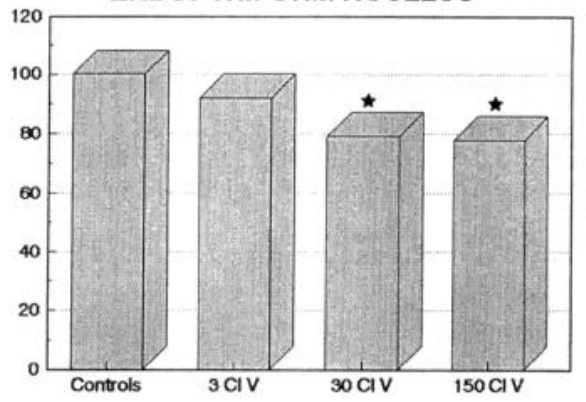

SOMATOSENSORY CORTEX

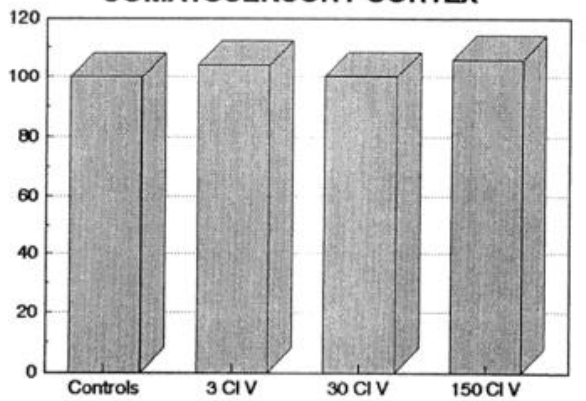

Figure 4. Progressive neuronal loss induced in limbic structures by repeated brief kindled seizures. The bars represent the average neuronal densities of the septal and temporal poles ipsilateral and contralateral to the stimulating electrode at each location, expressed as a percentage of the neuronal densities at equivalent locations in unstimulated electrode-implanted control rats. Significant differences $(0.001<p<0.05)$ in the average neuronal densities are indicated by the stars. There were also significant reductions in the neuronal density in temporal regions of CAla and $\mathrm{CA} 3 \mathrm{a}$ after three class $\mathrm{V}$ seizures, which are not reflected in the neuronal density calculated by averaging the septal and temporal densities (see text and Table 7 for details).

DG after 3 and 30 class V seizures (Cavazos and Sutula, 1990). In the present study, the hilus of the DG and the temporal poles of CAlc, CAla, and CA3a were particularly vulnerable to seizure-induced neuronal loss. Neuronal loss was observed in these locations after as few as three class V seizures. At this time point, no other limbic structures evaluated in this study exhibited significant neuronal loss.

After 30 class $\mathrm{V}$ seizures, significant decreases in neuronal density were observed in the pyramidal layer of CA3c, CA3a, CAlc, CAla, layers 2 and 6 of the lateral EC, layer 2 of the medial EC, and the rostral EN. After 150 class V seizures, significant decreases in neuronal density were also observed in layer 6 of the medial EC, in the temporal stratum granulosum of the DG, and possibly also in temporal CA2. Although the statistical analysis included corrections for multiple comparisons, the significance level of the decrease in neuronal density in CA2 $(p<$ 0.03 ) must be interpreted with caution. Nevertheless, the overall results demonstrated a hierarchy of selective vulnerability to seizure-induced damage in the limbic system, which progressed in a variety of locations in parallel with the continuing evolution of kindling. Neurons in the hilus of the DG were most vulner- able, followed by neurons in CA1, CA3, EN, EC, granule cells in the DG, and CA2.

Significant differences in neuronal densities as a function of stimulation site were not observed after 3,30 , or 150 class V seizures. However, the methods of this study do not exclude the possibility that at earlier stages of kindling there might be subtle differences in the regional patterns of neuronal loss that could reflect patterns of seizure propagation dependent on the specific circuitry activated by local stimulation of the perforant path, amygdala, or olfactory bulb.

In the hilus of the DG, the loss of polymorphic neurons was initially quite abrupt, with a $20 \%$ decrease in neuronal density after only three class $\mathrm{V}$ seizures. The decrease in neuronal density in the hilus reached $35 \%$ after 30 class V seizures, and was $48 \%$ after 150 class $\mathrm{V}$ seizures. In comparison, the onset of detectable neuronal loss was slower and of lesser magnitude in other limbic structures. This observation is consistent with previous evidence for a sensitive subpopulation of neurons in the hilus, which lack the calcium-binding proteins parvalbumin and calbindin and are exquisitely vulnerable to continuous seizures (status epilepticus) (Sloviter, 1989). 

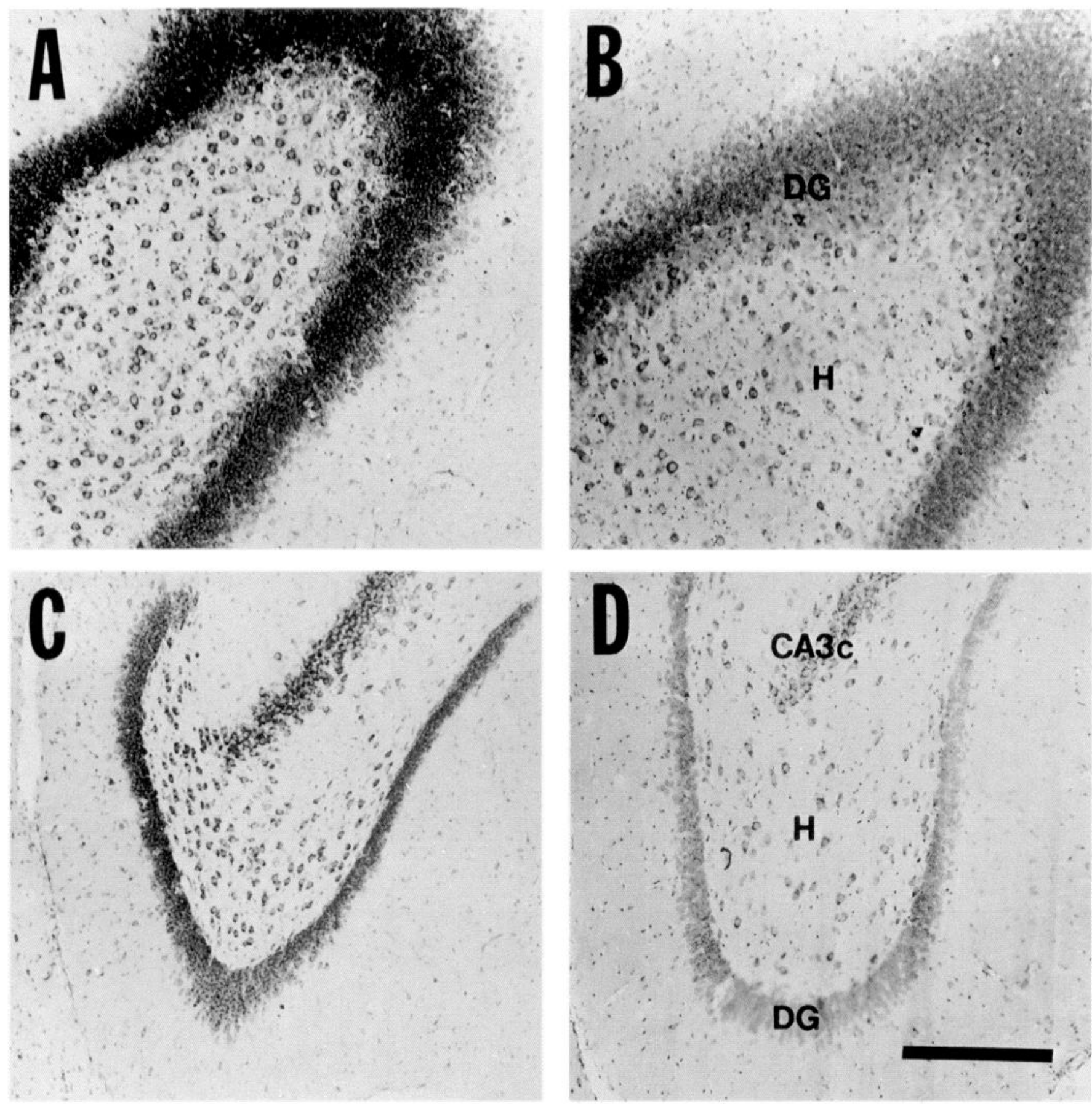

Figure 5. Neuronal loss induced in the DG by repeated brief kindled seizures. A, Higher magnification of the horizontal cresyl violet-stained section of the dorsal DG from the normal rat in Figure 1 demonstrates the normal distribution of neurons in the hilus and stratum granulosum at the septal pole of the hippocampal formation. $B$. Horizontal section at an equivalent location from a rat that experienced 150 generalized tonicclonic (class V) seizures induced by repeated kindling stimulation of the perforant path. There appears to be a reduction in the population of polymorphic neurons; stereological methods revealed an average $49 \%$ decrease in the polymorphic neurons at this site compared to controls. The neuronal density in the stratum granulosum at this level was not significantly different than controls. $C$, Higher magnification of the horizontal cresyl violet-stained section of the temporal pole of the hippocampal formation from the normal rat in Figure 3 demonstrates the distribution of neurons in the stratum granulosum and hilus of the DG at this level. $D$. Horizontal section of the temporal DG at an equivalent location from the rat that experienced 150 generalized tonic-clonic (class V) seizures (same rat as in $B$ ). There appears to be a reduction in the polymorphic neurons in the hilus; stereological methods revealed an average $46 \%$ decrease of neurons in the hilus compared to controls. The stratum granulosum appeared normal to visual inspection, but stereological methods revealed an average $20 \%$ reduction in the neuronal density in the stratum granulosum compared to controls. $D G$, stratum granulosum of the DG; $H$, hilus. Scale bar, $200 \mu \mathrm{m}$. 

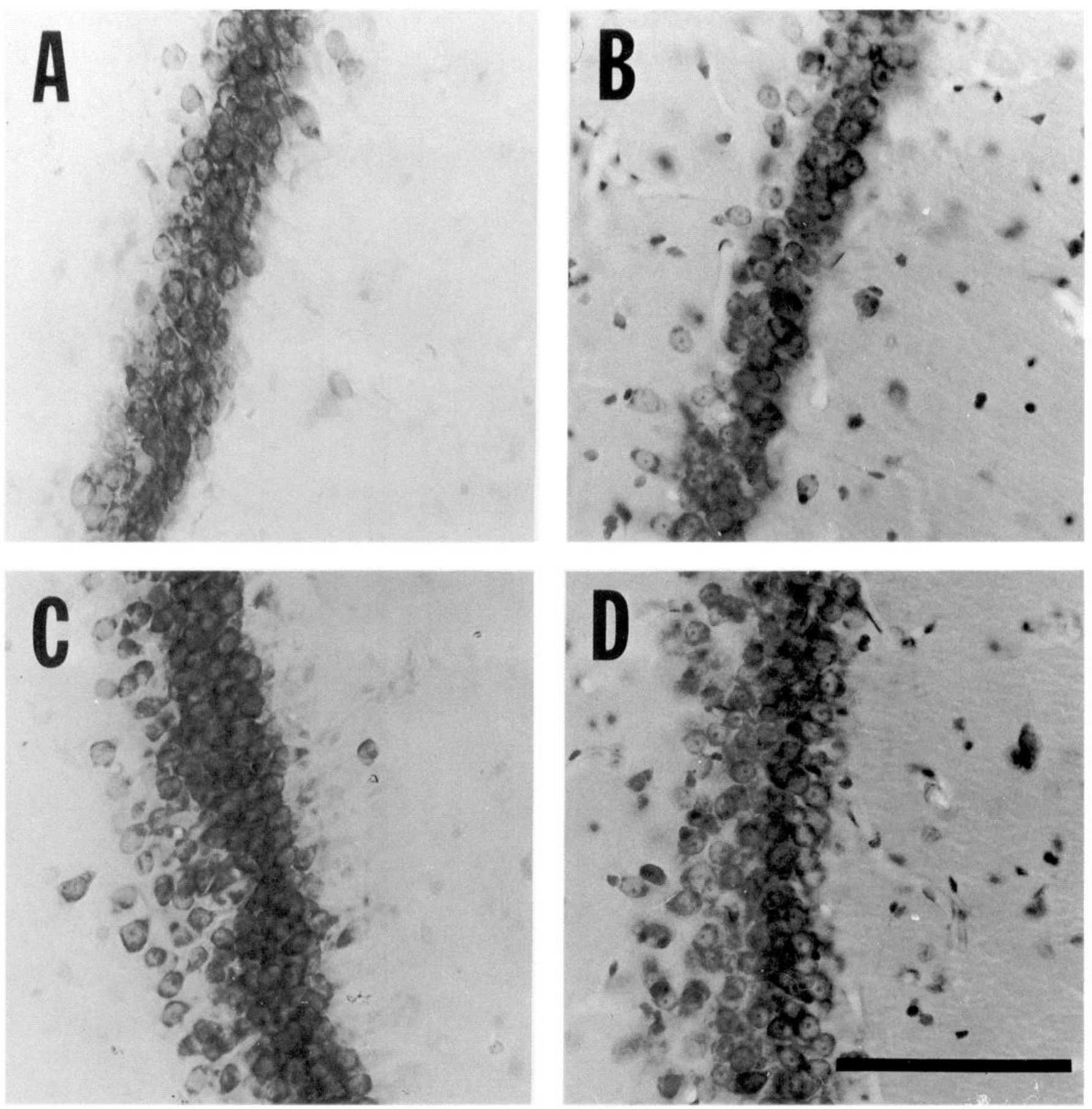

Figure 6. Neuronal loss induced in the stratum pyramidale of CA1c by repeated brief kindled seizures. $A$, Higher magnification of the horizontal section in Figure 2 demonstrates the normal distribution of neurons in the stratum pyramidale of CAlc at the septal pole of the hippocampal formation. $B$, Horizontal section at an equivalent location from a rat that had experienced 150 class $\mathrm{V}$ seizures (same rat as in Fig. $5 B, D$ ). Stereological methods revealed an average $19 \%$ decrease in the neuronal density in septal CAlc compared to controls. $C$, Higher magnification of horizontal section in Figure 3 demonstrates the normal neuronal distribution of neurons in the stratum pyramidale of CAlc at the temporal pole of the hippocampal formation. $D, A$ horizontal section of CAlc at an equivalent location from the rat that experienced 150 class $\mathrm{V}$ seizures (same rat as in $B$ and Fig. $5 B, D$ ). Stereological methods revealed that rats kindled to 150 class $\mathrm{V}$ seizures had an average $38 \%$ decrease in the neuronal density in temporal CAlc compared to controls. Scale bar, $200 \mu \mathrm{m}$.

There is heterogeneity of the transmitter systems in the limbic circuitry that undergoes neuronal loss in response to repeated seizures. It is not possible by the methods of this study to determine more specifically the identity of the seizure-sensitive neurons in the limbic populations that undergo neuronal loss during the evolution of kindling. Additional experiments using immunocytochemical techniques could further identify the neurons that are damaged by repeated kindled seizures (Kamphuis et al., 1986).

The observation of neuronal loss in the rostral EN is also of interest, as recent observations have suggested that neural circuitry in this region may play an important role in the initiation 

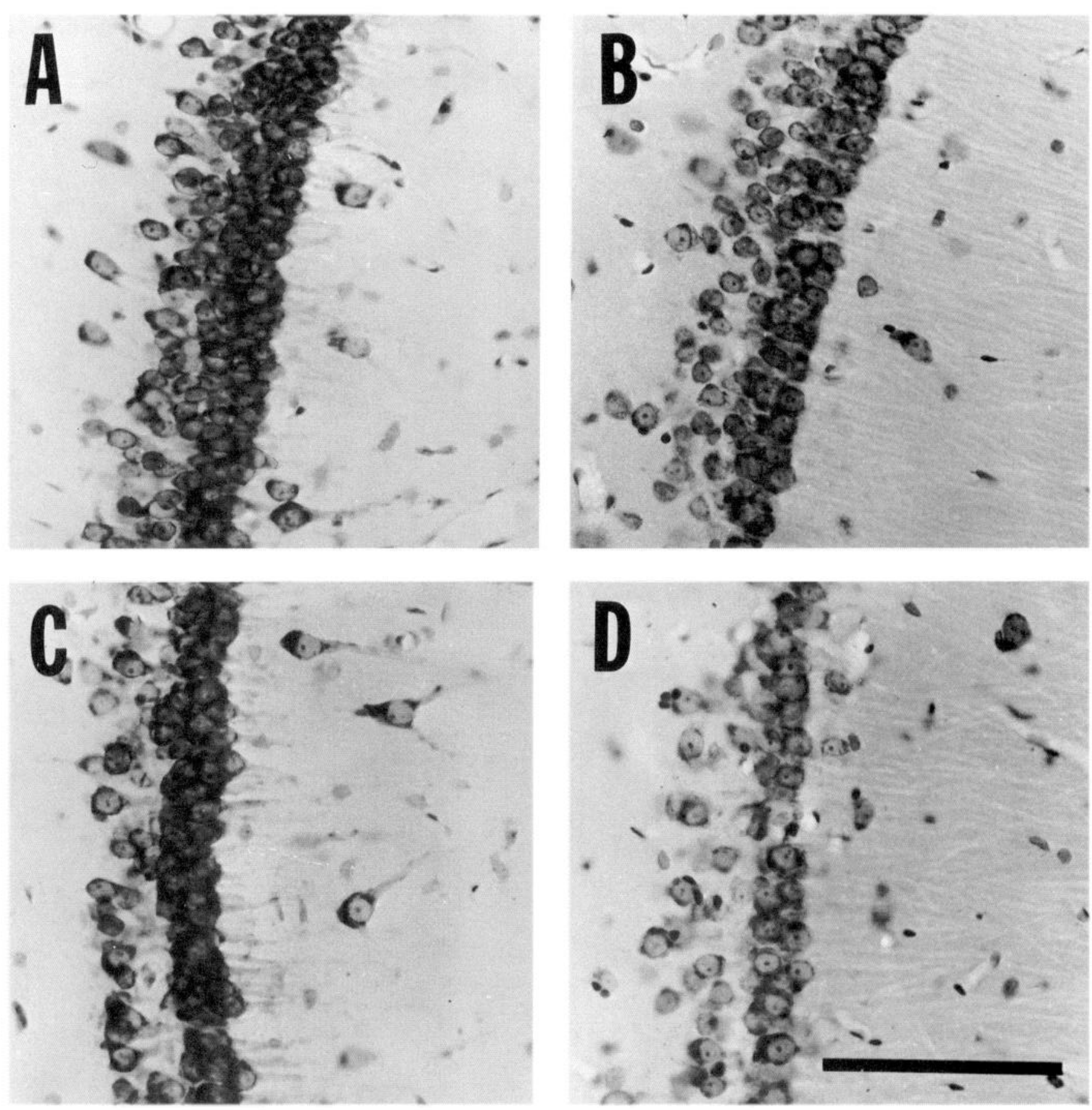

Figure 7. Neuronal loss induced in the stratum pyramidale of CAla by repeated brief kindled seizures. $A$, Higher magnification of the horizontal section of the dorsal hippocampal formation in Figure 2 demonstrates the normal distribution of neurons in the pyramidal layer of CAla at the septal pole of the hippocampus. $B$, Horizontal section of the pyramidal layer of CA1a at an equivalent location from a rat that experienced 150 class $\mathrm{V}$ seizures induced by repeated kindling stimulation of the perforant path (same rat as Figs. $5 B, D ; 6 B, D$ ). Stereological methods revealed that rats kindled to 150 class $\mathrm{V}$ seizures had an average $25 \%$ decrease in the neuronal density of the stratum pyramidale in septal CA1a compared to controls. $C$, Higher magnification of the horizontal section in Figure 3 demonstrates the normal distribution of neurons in the stratum pyramidale of CA la at the temporal pole of the hippocampal formation. $D$, A horizontal section of the CAla region at an equivalent location from a rat that experienced 150 class $\mathrm{V}$ seizures (same rat as in $B$ and Figs. $5 B, D ; 6 B, D$ ). Stereological methods revealed that rats kindled to 150 class $\mathrm{V}$ seizures had an average $44 \%$ decrease in the neuronal density of the stratum pyramidale of temporal CAla compared to controls. Scale bar, $200 \mu \mathrm{m}$.

of epileptic activity in limbic pathways (Piredda and Gale, 1985, 1986; Racine et al., 1988; Hoffman and Haberly, 1991). Additional studies will be necessary to evaluate more comprehensively the specific regions of this structure that may be affected by seizure-induced neuronal loss.

\section{Septotemporal variation of neuronal densities in normal rats}

In this study, there were distinct differences in neuronal density along the septotemporal axis in the hippocampal formation of normal Sprague-Dawley rats. The neuronal densities in the hilus 

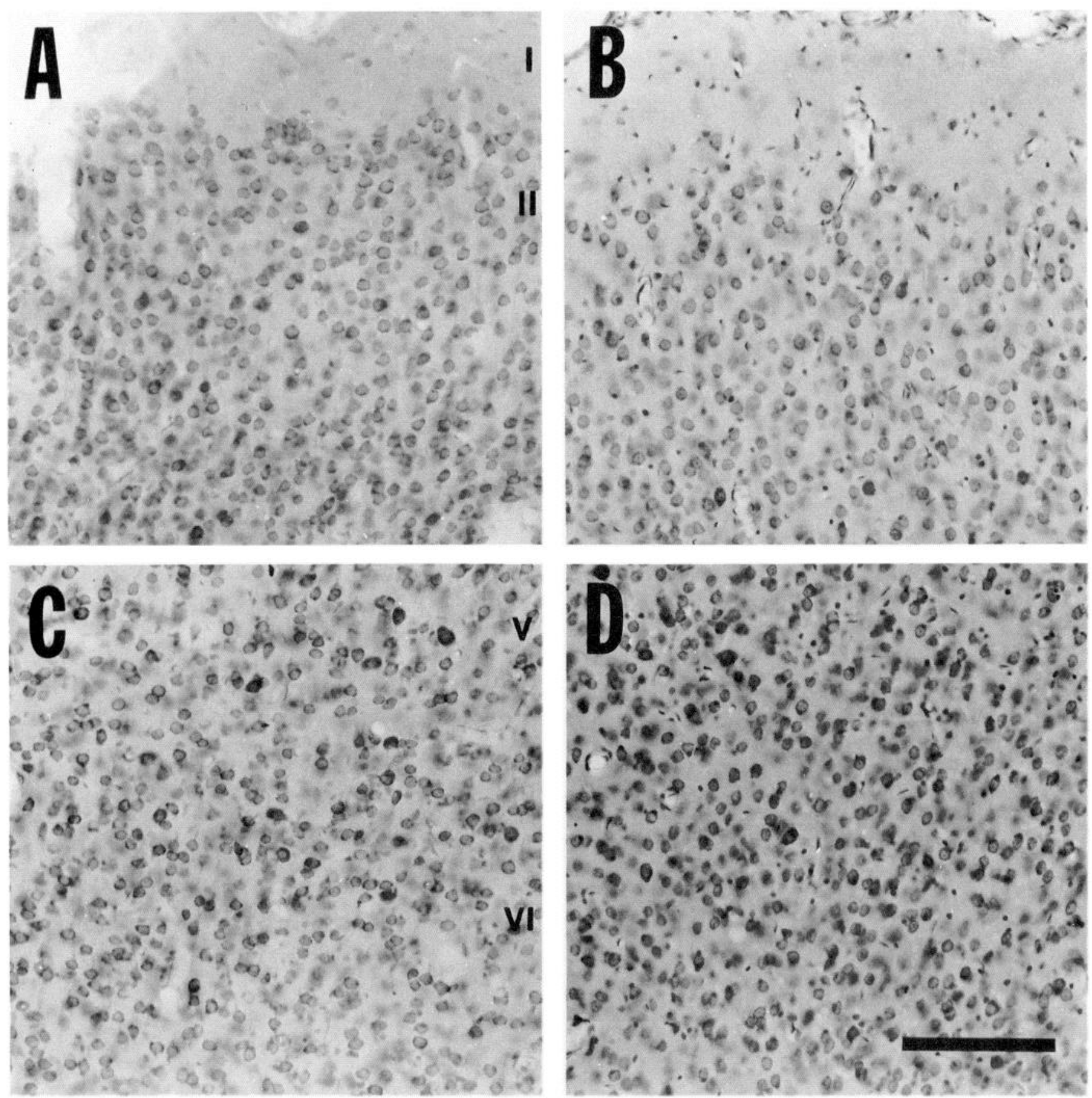

Figure 8. Neuronal density in layers 2 and 6 of the SSC in normal and kindled rats. A, Higher magnification of the horizontal section of the dorsal hippocampal formation and adjacent neocortex of a normal rat in Figure 1 demonstrates the distribution of neurons in the layer 2 of SSC. $B$, A horizontal section of layer 2 of the SSC at an equivalent location from a rat that experienced 150 class V seizures induced by repeated kindling stimulation of the perforant path (same rat as in Figs. $5 B, D ; 6 B, D ; 7 B, D$ ). Stereological methods revealed that rats kindled to 150 class $\mathrm{V}$ seizures had a neuronal density that did not differ from controls. $C$. Higher magnification of the horizontal section of the normal rat in Figure 1 demonstrates the distribution of neurons in the layer 6 of SSC. $D$, A horizontal section of the layer 6 of the SSC at an equivalent location from the rat that had experienced 150 class V seizures (same rat as in $B$ and Figs. $5 B, D ; 6 B, D ; 7 B, D$ ). Stereological methods revealed that the neuronal density at this location in rats kindled to 150 class $\mathrm{V}$ seizures did not differ from controls. $I, I I, V$, and $V I$ indicate the cortical layers. Scale bar, $200 \mu \mathrm{m}$.

of the DG, CA3a, and layer 6 of the medial EC were significantly higher in the temporal pole of the hippocampal formation than in the septal pole. In contrast, the neuronal density in CAla and layer 2 of the medial and lateral EC was significantly higher in the septal pole than in the temporal pole.

These observations confirm previous studies that have dem- onstrated significant differences in the anatomical organization of the hippocampus along its septotemporal axis in normal animals (Amaral et al., 1990). For example, the ratio of baskets cells to granule cells in the DG is about 1:140 in the septal pole of the DG, but is only 1:220 in the temporal pole of the DG (Seress and Pokorny, 1981). In addition, the mossy fiber path- 
way does not project to the inner molecular layer in septal (dorsal) DG in the normal rat, but does innervate the inner molecular layer in the temporal (ventral) pole (Cavazos et al., 1992). The functional effects of these differences in organization along the septotemporal axis are uncertain, but could influence information processing and epileptogenesis in hippocampal circuitry.

There are variations in physiological properties along the septotemporal axis. For example, there are differences in synaptic transmission along the septotemporal axis (Brazier, 1970; Racine et al., 1977; Gilbert et al., 1985; Bragdon et al., 1986). The relationship of these physiological differences to variations in anatomical organization along the septotemporal axis is unclear, but could influence the development of epilepsy, as the temporal pole is more vulnerable than the scptal pole to the development of kindling (Racine et al., 1977). The observation of greater vulnerability to seizure-induced neuronal loss in the temporal poles of the hilus of the DG and CAlc in rodents is also of interest, as the anterior pole of the human hippocampus (which corresponds to the rodent temporal pole) is frequently involved in human temporal lobe epilepsy, and may be more prominently involved in the lesion of hippocampal sclerosis (Babb et al., 1984).

\section{Relationship of kindling-induced neuronal loss to hippocampal sclerosis}

The lesion of hippocampal sclerosis, which is frequently observed in human epilepsy, is characterized by neuronal loss and gliosis in CA 1, CA3, and the hilus of the DG (Margerison and Corsellis, 1966; Mouritzen Dam, 1980; Babb et al., 1984; Babb and Brown, 1987; Gloor, 1991). Recent morphological studies have demonstrated that this pattern of neuronal loss in humans with epilepsy is frequently associated with sprouting in the mossy fiber pathway and other neurotransmitter systems, as well as dispersion of granule cells in the DG that may indicate developmental abnormalities (de Lanerolle et al., 1989; Represa et al., 1989; Sutula et al., 1989; Houser et al., 1990; Houser, 1991).

In this study, repeated brief seizures evoked by kindling induced neuronal loss in the hippocampus and DG in a pattern that resembled the principal features of hippocampal sclerosis. In human epilepsy, neuronal loss may be observed in all subregions of the hippocampus (Kim et al., 1990), and usually affects the anterior pole most prominently, which corresponds to the temporal pole in the rat. The observations that repeated kindled seizures eventually induce neuronal loss in "resistant" neuronal populations such as granule cells in the DG and pyramidal neurons in $\mathrm{C} \Lambda 2$, and more prominently reduces neuronal populations in the temporal pole of the rat, thus have a remarkable parallel to human pathological observations. These observations suggest that kindling and human temporal lobe epilepsy could share common mechanisms, and also raise the possibility that kindling could play a role in the development and natural history of temporal lobe epilepsy.

Repeated kindled seizures in rats also induced neuronal loss in other limbic structures such as the EC and the rostral EN. These findings suggest that seizure-induced damage may not be limited to the hippocampus, and suggest the possibility that extrahippocampal limbic pathways may undergo structural reorganization as a result of repeated seizures. The neuronal loss induced in hippocampal and limbic circuitry by brief repeated seizures could also play a role in the memory and cognitive disturbances that are frequently encountered in temporal lobe epilepsy (Sutula, 1990).

For over a century, there has been controversy about hippocampal sclerosis as a cause or effect of the repeated, brief seizures that are a feature of temporal lobe epilepsy (Babb and Brown, 1987; Gloor, 1991). The observations of this study provide strong evidence that repeated brief seizures induce hippocampal damage in a pattern that resembles hippocampal sclerosis, but do not exclude the possibility that neuronal loss and the associated sprouting, reactive synaptogenesis, and synaptic reorganization might also contribute to enhanced susceptibility to further seizures. The functional effects of neuronal loss, sprouting, alterations in inhibition, and the numerous cellular and molecular alterations in limbic circuitry associated with the development of seizures are extremely complex, and may vary dynamically during the generation of seizures in limbic circuitry reorganized by structural lesions and seizure-induced neuronal loss (Sutula et al., 1992). This study has identified a variety of regions in limbic circuitry in which these complex issues might be addressed in an effort to understand the cellular and molecular processes that contribute to the disorder of temporal lobe epilepsy.

The present results are consistent with the possibility that excitotoxic mechanisms could contribute to neuronal damage in the limbic system in association with repeated brief seizures. The results provide a rationale for development of drugs that could reduce excitotoxic damage, and modify structural alterations induced by seizures in limbic circuitry. Previous studies have demonstrated that brief treatment that suppresses intense acute seizures in the kainic acid model of status epilepticus can modify excitotoxic damage in the DG, prevent reactive mossy fiber sprouting, and reduce susceptibility to chronic seizures (Sutula et al., 1992). Therapeutic efforts to reduce excitotoxic damage after repeated brief seizures may also modify long-term structural and functional alterations in limbic circuitry that contribute to abnormal excitability in chronic epileptic models and human epileptic syndromes.

\section{References}

Amaral DG (1978) A Golgi study of cell types in the hilar region of the hippocampus in the rat. J Comp Neurol 182:851-914.

Amaral DG, Ishizuka N, Claiborne B (1990) Neurons, numbers and the hippocampal network. Understanding the Brain Through the Hippocampus 83:1-11.

Babb T, Brown W (1987) Pathological findings in epilepsy. In: Surgical treatment of the epilepsies (Engel $\mathbf{J}$, ed), pp 511-540. New York: Raven.

Babb T, Pretorius W, Davenport C, Licb J, Crandall P (1984) Tcmporal lobe volumetric cell densities in temporal lobe epilepsy. Epilepsia 25:721-732.

Ben Ari Y (1985) Limbic seizure and brain damage produced by kainic acid: mechanisms and relevance to human temporal lobe epilepsy. Neuroscience 14:375-403.

Bertram E, Lothman E (1993) Morphometric effects of intermittent kindled seizures and limbic status epilepticus in the dentate gyrus of the rat. Brain Res 603:25-31.

Bragdon A, Taylor D, Wilson W (1986) Potassium-induced epileptiform activity in area CA3 varies markedly along the septotemporal axis of the rat hippocampus. Brain Res 378:169-173.

Brazier MA (1970) Regional activities within the human hippocampus and hippocampal gyrus. Exp Neurol 26:354-368.

Cavazos JE, Sutula T (1990) Progressive ncuronal loss induced by kindling: a possible mechanism for mossy fiber synaptic reorganization and hippocampal sclerosis. Brain Res 527:1-6.

Cavazos J, Sutula T (1991) Pyramidal cell loss in CA1 and CA3 
induced by kindling: evidence that repeated sporadic seizures may cause hippocampal sclerosis. Epilepsia 32:66.

Cavazos J, Golarai G, Sutula T (1991) Mossy fiber synaptic reorganization induced by kindling: time course of development, progression, and permanence. J Neurosci 11:2795-2803.

Cavazos JE, Golarai G, Sutula T (1992) Septotemporal variation of the supragranular projection of the mossy fiber pathway in the dentate gyrus of normal and kindled rats. Hippocampus 2:363-372.

Choi D, Rothman S (1990) The role of glutamate neurotoxicity in hypoxic-ischemic neuronal death. Annu Rev Neurosci 13:171-182.

Clarke PG (1992) How inaccurate is the Abercrombie correction factor for cell counts? Trends Neurosci 15:211-212.

Crandall JE, Bernstein J, Boast C, Zornetzer S (1979) Kindling in the rat hippocampus: absence of dendritic alterations. Behav Neural Biol 27:516-522

de Lanerolle N, Kim J, Robbins R, Spencer D (1989) Hippocampal interneuron loss and plasticity in human temporal lobe epilepsy. Brain Res 495:387-395.

Gilbert M, Racine R, Smith GK (1985) Epileptiform burst responses in ventral versus dorsal hippocampal slices. Brain Res 361:389-391.

Gloor P (1991) Mesial temporal sclerosis: historical background and an overview from a modern prospective. In: Epilepsy surgery (Luders H, ed), pp 689-703. New York: Raven.

Goddard G, McIntyre D, Leech C (1969) A permanent change in brain function resulting from daily electrical stimulation. Exp Neurol 25: 295-330.

Hauser WA (1983) Status epilepticus: frequency, etiology, and neurological sequelae. Adv Neurol 34:3-14.

Hoffman W, Haherly L (1991) Bursting-induced epileptiform EPSPs in slices of piriform cortex are generated by deep cells. J Neurosci 11 : 2021-2031.

Houser CR (1991) Granule cell dispersion in the dentate gyrus of humans with temporal lobe epilepsy. Brain Res 535:195-204.

Houser C, Miyashiro J, Swartz B, Walsh G, Rich J, Delgado-Escueta AV (1990) Altered patterns of dynorphin immunoreactivity suggest mossy fiber reorganization in human hippocampal epilepsy. J Neurosci 10:276-282.

Kamphuis W, Wadman W, Buljs KM, Lopes da Silva FH (1986) Decrease in number of hippocampal gamma-aminobutyric acid (GABA) immunoreactive cells in the rat kindling model of epilepsy. Exp Brain Res 64:491-495.

Kim J, Guimaraes PO, Shen MY, Masukawa LM, Spencer D (1990) Hippocampal neuronal density in temporal lobe epilepsy with and without gliomas. Acta Neuropathol (Berl) 80:41-45.

Konigsmark B (1969) Methods for the counting of neurons. In: Contemporary research methods in neuroanatomy (Nauta W, Ebbesson S, eds), pp 315-340. Berlin: Springer.

Margerison JH, Corsellis J (1966) Epilepsy and the temporal lobes. Brain 89:499-530.

McNamara J (1986) The kindling model of epilepsy. Adv Neurol 44: 303-318.

Meldrum B, Vigouroux R, Brierley J (1973) Systemic factors and epileptic brain damage: prolonged seizures in paralyzed artificially ventilated baboons. Arch Neurol Psychol 29:82-87.

Mouritzen Dam A (1980) Epilepsy and neuron loss in the hippocampus. Epilepsia 21:617-629.

Nadler J, Cuthbertson G (1980) Kainic acid neurotoxicity toward the hippocampal formation: dependence on specific excitatory pathways. Brain Res 195:47-56.
Olney I, Rhee V, Ho O (1974) Kainic acid: a powerful neurotoxic analogue of glutamate. Brain Res 77:507-512.

Piredda S, Gale K (1985) A crucial epileptogenic site in the deep prepiriform cortex. Nature 317:623-625.

Piredda S, Gale K (1986) Role of excitatory amino acid transmission in the genesis of seizures elicited from the deep prepiriform cortex. Brain Res 377:205-210.

Racine R (1972) Modification of seizure activity by electrical stimulation. II. Motor seizure. Electroencephalogr Clin Neurophysiol 32: 281-294.

Racine R, Rose P, Burnham WM (1977) Afterdischarge thresholds and kindling rates in dorsal and ventral hippocampus and dentate gyrus. Can J Neurol Sci 4:273-278.

Racine R, Mosher M, Kairiss E (1988) The role of the pyriform cortex in the generation of interictal spikes in the kindled preparation. Brain Res 454:251-263.

Represa A, le Gall la Salle G, Ben-Ari Y (1989a) Hippocampal plasticity in the kindling model of epilepsy in rats. Neurosci Lett 99:345350.

Represa A, Robain O, Tremblay E, Ben-Ari Y (1989b) Hippocampal plasticity in childhood epilepsy. Neurosci Lett 99:351-355.

Seress L, Pokorny J (1981) Structure of the granular layer of the rat dentate gyrus: a light microscopic and Golgi study. J Anat 133:181195.

Sloviter R (1983) Epileptic brain damage in rats induced by sustained electrical stimulation of the perforant path. I. Acute electrophysiological and light microscopic studies. Brain Res Bull 10:675-697.

Sloviter R (1987) Decreased hippocampal inhibition and a selective loss of interneurons in experimental epilepsy. Science 235:73-75.

Sloviter R (1989) Calcium-binding protein (calbindin-D28) and parvalbumin immunocytochemistry: localization in the rat hippocampus with specific reference to the sclective vulncrability of hippocampal neurons to seizure activity. J Comp Neurol 280:183-196.

Sloviter R, Damiano B (1981) Sustained electrical stimulation of the perforant path duplicates kainate-induced electrophysiological effects and hippocampal damage in rats. Neurosci Lett 24:279-284.

Stringer JL, Lothman EW (1992) Bilateral maximal dentate activation is critical for the appearance of an afterdischarge in the dentate gyrus. Neuroscience 46:309-314.

Sutula T (1990) Experimental models of temporal lobe epilepsy-new insights from the study of kindling and synaptic reorganization. Epilepsia 31:45-54.

Sutula T, Steward O (1986) Quantitative analysis of synaptic potentiation during kindling of the perforant path. J Neurophysiol 56:732745

Sutula T, He XX, Cavazos J, Scott G (1988) Synaptic reorganization in the hippocampus induced by abnormal functional activity. Science 239:1147-1150.

Sutula T, Cascino G, Cavazos J, Parada I, Ramirez L (1989) Mossy fiber synaptic reorganization in the epileptic human temporal lobe. Ann Neurol 26:321-330.

Sutula T, Golarai G, Cavazos J (1992a) Assessing the functional significance of mossy fiber sprouting. Epilepsy Res [Suppl] 7:251-259.

Sutula T, Cavazos J, Golarai G (1992b) Alteration of long-lasting structural and functional effects of kainic acid in the hippocampus by brief treatment with phenobarbital. J Neurosci 12:4173-4187.

West $M$, Danscher $G$, Gydesen $H$ (1978) A determination of the volumes of the layers of the rat hippocampal region. Cell Tissue Res 188:345-359. 